\title{
REVIEWS
}

\section{Novel High Performance Materials. Calixarene Derivatives Containing Protective Groups and Polymerizable Groups for Photolithography, and Calixarene Derivatives Containing Active Ester Groups for Thermal Curing of Epoxy Resins}

\author{
Tadatomi NishiKubo, ${ }^{\dagger}$ Atsushi Kameyama, ${ }^{*}$ and Hiroto Kudo \\ Department of Applied Chemistry, Faculty of Engineering, Kanagawa University, \\ Rokkakubashi, Kanagawa-ku, Yokohama 211-8686, Japan \\ *Department of Chemistry, Faculty of Engineering, Kanagawa University, \\ Rokkakubashi, Kanagawa-ku, Yokohama 221-8686, Japan
}

(Received November 29, 2002; Accepted January 14, 2003)

\begin{abstract}
This paper reviews our recent studies on the syntheses and functions of novel calixarene derivatives with excellent thermal stability as high performance materials. Calixarene derivatives containing protective groups such as tert-butoxycarbonyl ( $t$-Boc), trimethylsilyl (TMS), and cyclohexenyl (CHE) groups were successfully prepared by the reaction of certain calixarenes, $p$-methylcalix[6]arene (1a), p-tert-butylcalix[8]arene (1c), and $C$ methylcalix[4]resorcinarene (1d) with the corresponding protecting reagents. Calixarene containing radically polymerizable groups such as methacryloyl groups and cationic polymerizable groups such as propargyl, vinyl ether groups were prepared in good yields. Calixarene derivatives containing cyclic ethers such as oxirane, oxetane, and spiro orthoesters were also prepared. Calixarene derivatives thus obtained had good film forming property and thermal stability. It was proved that the photoinduced deprotection of the calixarene derivatives containing protective groups in the presence of a photo-acid generator proceeded easily to give the corresponding calixarenes with phenol groups. Photoinitiated polymerization of the calixarenes with various polymerizable groups using suitable photoinitiators in the film state proceeded efficiently to produce crosslinked films. Furthermore, thermal curing of epoxy resins with calixarenes (1a, 1c, 1d), and calixarenes containing active ester groups using certain catalysts were studied to found that the calixarenes were useful curing agents for epoxy resins.
\end{abstract}

KEY WORDS Calixarene / Thermal Stability / Protective Group / Polymerizable Group / Photoinduced Deprotection / Radical Polymerization / Cationic Polymerization / Thermal Curing / Epoxy Resin /

Calixarenes are cyclic oligomers prepared ${ }^{1}$ ordinarily from the reaction of phenols with aldehydes, and have attracted much interest in the field of host-guest chemistry. ${ }^{2}$ Therefore, over the last 20 years, synthesis ${ }^{3}$ of various calixarene derivatives and chemical modification $^{4,5}$ of calixarenes have been studied in attempting to induce the targeted character. We can consider that calixarene derivatives have further advantage in synthetic organic chemistry as starting materials due to polyfunctional hydroxyl groups, which are readily modified to various functional groups. That is, in polymer synthesis, calixarene derivatives can also be used as multifunctional initiators for the synthesis of starshaped polymers. Kennedy and his co-workers ${ }^{6}$ reported the synthesis of a star-shaped polymer with eight arms of poly(iso-butylene) using calix[8]arene derivative as an initiator. Sawamoto and his co-workers ${ }^{7}$ succeeded in producing certain star-shaped polymer with 4-8 arms of poly(methyl methacrylate) using cal-

${ }^{\dagger}$ To whom correspondence should be addressed. ixarene derivative as initiator.

Recently, it was also suggested that calixarenes have unique characteristics such as small molecular size, good film-forming properties, ${ }^{8,9}$ high glass transition temperature ${ }^{10}\left(T_{\mathrm{g}}\right)$, excellent thermal stability, ${ }^{10,11}$ many reactive groups such as hydroxyl groups in small molecule, and so on. For example, Fujita et al. found ${ }^{8}$ that hexa-acetate of $p$-methylcalix[6]arene could be used as a negative type resist with ultrahigh resolution in electron beam lithography.

Photoinduced deprotection of certain protective groups at polymer side chains using photo-acid generators (PAG)s is applied for lithography based on the concept as chemical amplification. ${ }^{12}$ In chemical amplification systems, photo generation of acids from PAG followed by acids catalyzed deprotection by heating can introduce polarity exchange of the matrix with high efficiency, that is, from hydrophobic property to hydrophilic one of the matrix. Ueda and his co-workers recently reported ${ }^{13,14}$ 
on three-component negative-working alkaline-developable photoresist based on calix[4]resorcinarene, a cross-linker, and a photo-acid generator. They also reported $^{15-17}$ the synthesis of octa-O-tert-butyl carbonated $C$-hexylcalix[4]resorcinarene and its derivatives for positive-working alkaline-developable photoresist.

Meanwhile, UV and EB curing systems have been of great interest, ${ }^{18,19}$ and have been introduced in the fields of coatings, printing inks, photofabrications, adhesives, and solder masks. These systems are among the important methods of reducing use of harmful organic solvents, carbon dioxide due to the combustion of fossil fuels, and energy. Recently, these UV and EB curing systems have been further extended in some new technology fields such as microelectronics, micromachines, three-dimensional fabrications, liquid crystal displays, optical media, and optoelectronic materials. In these curing systems, radically polymerizable polyfunctional (meth)acrylate monomers and oligomers have been widely used with appropriate photoinitiators, because these monomers and oligomers have high photochemical reactivity to produce the crosslinked insoluble lumps or films having excellent mechanical and physical properties. However, it was pointed out that some methacrylate monomers with low viscosity cause skin irritability, ${ }^{20}$ an undesirable property for handling them during these processes.

Photo-initiating cationic polymerizations of polyfunctional epoxy compounds and polyfunctional vinyl ether compounds have been of interes $\mathrm{f}^{21}$ as second generation's UV curing materials, since these monomers and oligomers have also high photochemical reactivity in the presence of appropriate photo-generating cationic catalysts and seem to cause little skin irritability. Polyfunctional vinyl ether monomers and oligomers were normally synthesized by the addition reaction of acetylene with polyfunctional alcohols or by the substitution reaction ${ }^{22,23}$ of polyfunctional phenols and carboxylic acids with 2-chloroethyl vinyl ether (CEVE) with the use of a phase-transfer catalysis.

The authors have reported ${ }^{2-26}$ new methods for the synthesis of polyfunctional vinyl ether monomers and oligomers by the regioselective addition reaction of glycidyl vinyl ether with acyl chlorides and silyl chlorides followed by the condensation reaction of the resulting monomers containing reactive chloromethyl groups with dicarboxylic acids using quaternary onium salts or crown ethers as the multifunctional catalysts. Crivello et al. reported ${ }^{27,28}$ that polyfunctional 1-propenyl ether monomers, which have mostly the same photochemical reactivity with polyfunctional vinyl ether monomers, were prepared by the isomerization of the corresponding allyl ether monomers.
Furthermore, thermal curing resins such as epoxy resins have also been used as encapsulant for semiconductor devices and intercalation insulating materials in the field of electronics, because they have good properties such as high $T_{\mathrm{g}}$ and good thermal stability as well as those for UV cured resins. To develop new cured materials with excellent chemical and physical properties for the great demand in those fields, new molecular design of curing agents are needed. Nishikubo has reported new curing reactions ${ }^{29-34}$ of epoxy resins with active carboxylic esters, which provide cured resins without hydroxyl groups. The authors considered that calixarenes could be used as curing agents for thermal curing epoxy resins with excellent properties, because oxirane groups of epoxy resins react easily with phenols and their active ester groups in the presence of suitable catalysts.

From all these background, we consider new advantage of calixarenes and their derivatives, and following molecular designs (Scheme 1). The first design of calixarene derivatives is the synthesis of photoreactive calixarene derivatives containing protective groups for the application to nano-lithography. The second design is the synthesis of calixarene derivatives containing photo-polymerizable groups for the application of high performance photo-curable materials. The third one of calixarenes is the application for the high performance epoxy resins by the reaction with calixarene derivatives.

In this article, we would like to report on the synthesis, characterization, and photochemical reaction of $p$-alkylcalixarene and $C$-methylcalix[4]resorcinarene derivatives containing protective groups. Synthesis, characterization, and photochemical reaction of $p$-alkylcalixarene, and $C$-methylcalix[4]resorcinarene derivatives containing radically polymerizable groups, cationically polymerizable groups, and pendant cyclic ether groups such as oxirane, oxetane, and spiro ortho ester groups are also described. Furthermore, thermal curing reaction of epoxy resins with calixarenes and calixarene derivatives containing ester groups using quaternary onium salts as catalysts, and properties of the cured materials are also reported.

\section{CALIXARENES CONTAINING PROTECTIVE GROUPS $^{35}$}

\section{Synthesis}

Photoinduced deprotection of the calixarenes containing protective groups induces polarity exchange of the calixarene derivatives, which will be applied for photolithography. Therefore, we designed calixarene derivatives with protective groups such as tert- 


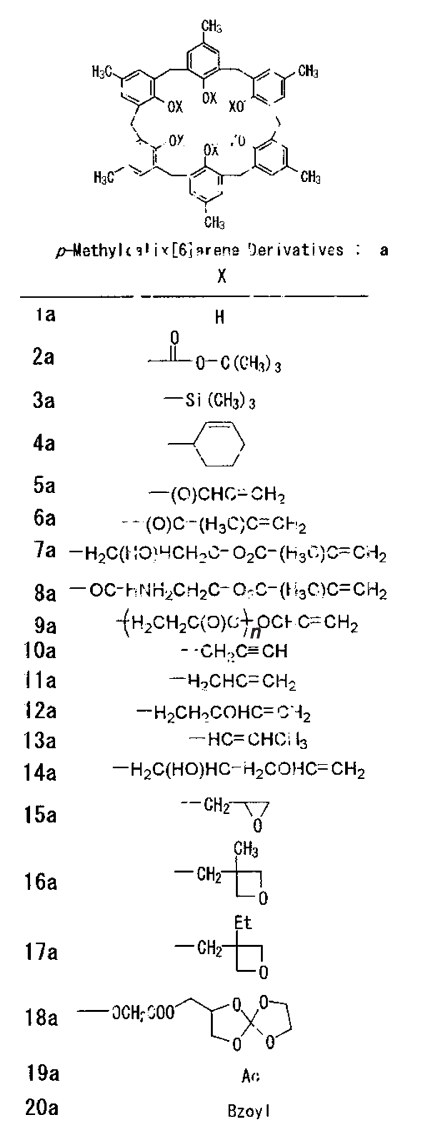


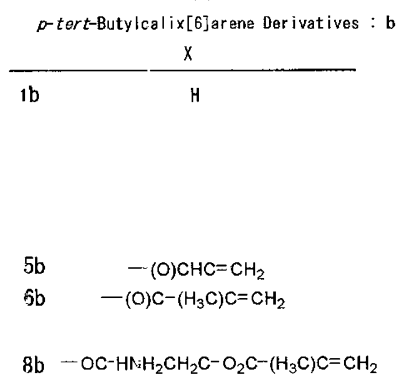

8b $-\mathrm{OC}-\mathrm{H}_{\mathrm{i}} \mathrm{H}_{2} \mathrm{CH}_{2} \mathrm{C}-\mathrm{O}_{2} \mathrm{C}-\left(\mathrm{H}_{3} \mathrm{C}\right) \mathrm{C}=\mathrm{CH}_{2}$

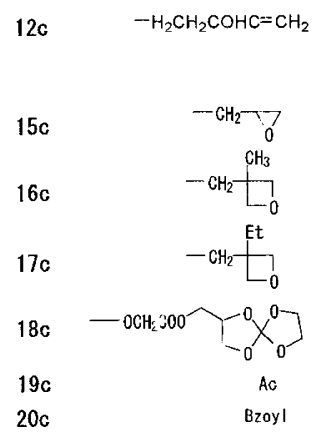

$4 \mathrm{c}$
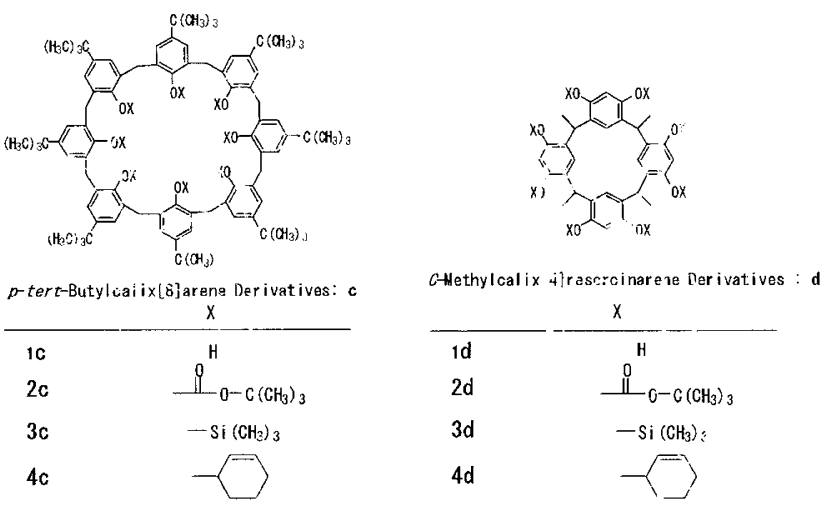

$4 d$

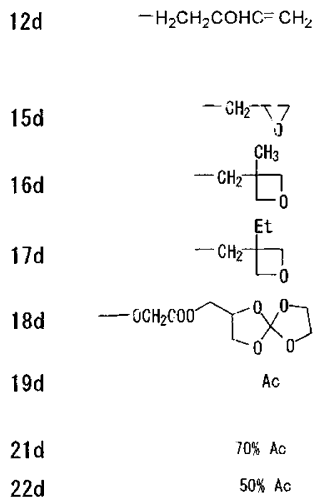

Scheme 1.

butoxycarbonyl ( $t$-BOC), trimethylsilyl ether (TMSE), and cyclohexenyl ether (CHE) groups.

Calixarene derivatives containing $t$-BOC groups 2a, 2c, and 2d were prepared in high yields, respectively, by the reaction of calixarenes $p$ methylcalix[6]arene 1a, p-tert-butylcalix[8]arene 1c, and $C$-methylcalix[4]resorcinarene $\mathbf{1 d}$ with di-tertbutyl dicarbonate using trietylamine as a base in pyridine at room temperature for $24 \mathrm{~h}$ (Scheme 2). Ueda et al. ${ }^{16,17}$ recently reported the synthesis of similar $C$-calix[4]resorcinarene derivatives containing $t$-BOC groups.

Calixarene derivatives containing TMSE groups as protective groups $\mathbf{3 a}, \mathbf{3 c}$, and $\mathbf{3 d}$ were successfully prepared, respectively, in high yields by the reaction of 1a, 1c, and 1d with excess amount of 1,1,1,3,3,3hexamethyldisilazane (HMDS) using catalytic amount of trimethylsilyl chloride (TMSC) as an accelerator in THF at reflux temperature for $48 \mathrm{~h}$.

Calixarene derivatives containing CHE groups $\mathbf{4 a}$, 4c, and 4d were successfully prepared, respectively, by the reaction of $\mathbf{1 a}, \mathbf{1 c}$, and 1d with slightly excess amount of 3-bromocyclohexene (BCH) using $\mathrm{KOH}$ and $\mathrm{TBAB}$ as a phase transfer catalyst in NMP at $60^{\circ} \mathrm{C}$ for
$48 \mathrm{~h}$. The structures of the obtained calixarene derivatives prepared were well identified by IR and ${ }^{1} \mathrm{H}$ NMR spectral data, and elemental analysis.

Calixarene derivatives $\mathbf{2 a}, \mathbf{2 c}$, and $\mathbf{2 d}$ containing $t$ BOC groups and $\mathbf{4 a}, \mathbf{4 b}$, and $\mathbf{4 c}$ containing CHE groups were soluble in common organic solvents excepting methanol and 2-propanol. On the other hand, the calixarene derivative 3a containing TMSE group was soluble in acetone, ethyl acetate, 1,4-dioxane, chloroform, and NMP, and was insoluble in DMF and DMAc. Calixarene $3 \mathbf{c}$ was only soluble in 1,4-dioxane, chloroform, toluene, and THF, and calixarene $\mathbf{3 d}$ was soluble in ethyl acetate, 1,4-dioxene, chloroform, and THF. This shows that the solubility of calixarene derivatives $\mathbf{3 a}$, $\mathbf{3 c}$, and 3d containing TMSE groups in organic solvents, especially in aprotic polar solvents, was low due to hydrophobicity of the pendant TMSE groups in calixarenes.

The deprotection temperature of calixarene derivatives containing certain protective groups was examined using TGA analysis. As shown in Figure 1, $t$-BOC groups in $\mathbf{2 a}, \mathbf{2 c}$ and $\mathbf{2 d}$ released reasonable amounts of carbon dioxide and isobutylene to form corresponding calixarenes such as 1a, $1 \mathrm{c}$ and $1 \mathrm{~d}$ over $200^{\circ} \mathrm{C}$, respec- 

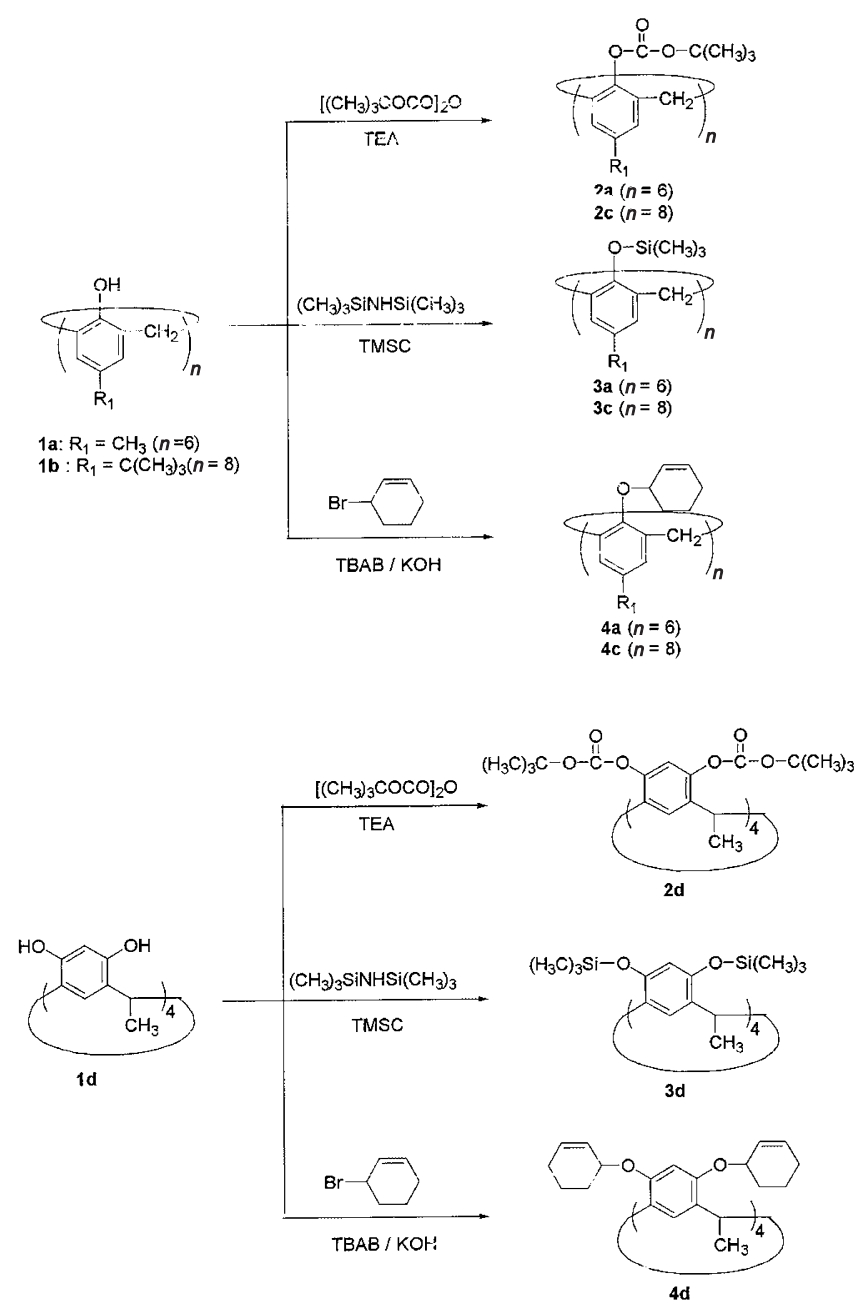

Scheme 2.

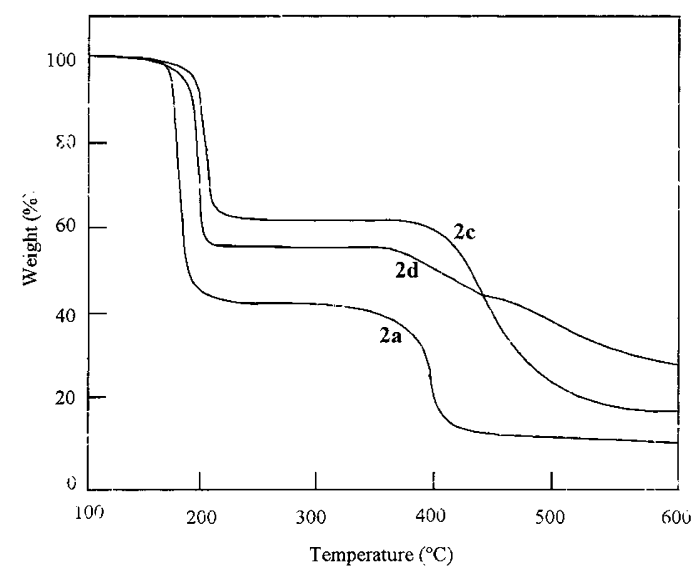

Figure 1. TGA curve of calixarene $\mathbf{2 a}, \mathbf{2 c}$, and $\mathbf{2 d}$ containing pendant $t$-BOC groups at a heating rate of $10^{\circ} \mathrm{C} \mathrm{min}^{-1}$ under nitrogen atmosphere.

tively.

The temperatures at $5 \%$ or $10 \%$ weight loss of mass are summarized in Table I. The temperatures at $T_{\mathrm{d}} 5 \%$ and $T_{\mathrm{d}}{ }^{10 \%}$ of calixarene derivative 2a were 178 and $184^{\circ} \mathrm{C}$, respectively. The $T_{\mathrm{d}}{ }^{5 \%}$ and $T_{\mathrm{d}}{ }^{10 \%}$ of calixarene derivative $2 \mathrm{c}$ were 173 and $174^{\circ} \mathrm{C}$, respectively. Fur-
Table I. TGA data of CRA and $p$-alkylcalix[n]arene derivatives containing various protecting groups ${ }^{\mathrm{a}}$

\begin{tabular}{ccc}
\hline Calixarene & $T_{\mathrm{d}}{ }^{5 \% \mathrm{~b}}$ & $T_{\mathrm{d}}{ }^{10 \% \mathrm{c}}$ \\
\hline $\mathbf{2 a}$ & 178 & 184 \\
$\mathbf{2 c}$ & 189 & 194 \\
$\mathbf{2 d}$ & 173 & 174 \\
$\mathbf{3 a}$ & 328 & 348 \\
$\mathbf{3 c}$ & 400 & 424 \\
$\mathbf{3 d}$ & 293 & 310 \\
$\mathbf{4 a}$ & 184 & 194 \\
$\mathbf{4 c}$ & 180 & 197 \\
$\mathbf{4 d}$ & 185 & 192 \\
\hline
\end{tabular}

${ }^{\mathrm{a}} \mathrm{TGA}$ was performed at a heating rate of $10^{\circ} \mathrm{C} \mathrm{min}^{-1}$ under nitrogen atmosphere. ${ }^{\mathrm{b}} T_{\mathrm{d}}{ }^{5 \%}$ : The temperature at $5 \%$ weight loss. ${ }^{\mathrm{c}} T_{\mathrm{d}} 10 \%$ : The temperature at $10 \%$ weight loss.

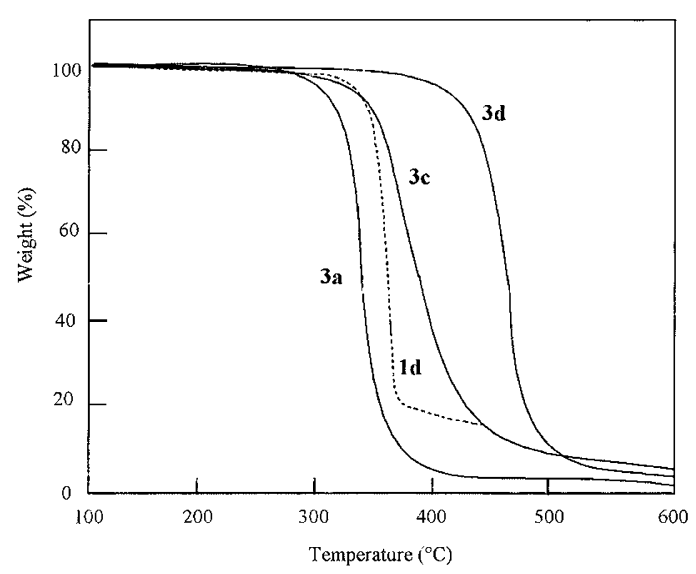

Figure 2. TGA curve of calixarenes $\mathbf{3 a}, \mathbf{3 c}$, and $\mathbf{3 d}$ containing pendant $t$-BOC groups and $\mathbf{1 d}$ at a heating rate of $10^{\circ} \mathrm{C} \mathrm{min}^{-1}$ under nitrogen atmosphere.

thermore, the $T_{\mathrm{d}}{ }^{5 \%}$ and $T_{\mathrm{d}}{ }^{10 \%}$ of calixarene derivative 2d were 189 and $194^{\circ} \mathrm{C}$, respectively. It is suggested that calixarene derivatives with backbone of 1a had relatively lower deprotection temperature, which seemed to indicate a more suitable character for a chemically amplified resist, than those of calixarene derivatives with backbones of $\mathbf{1 c}$ and $\mathbf{1 d}$.

As shown in Figure 2, TGA curve of 3a was similar to that of 1d, although initial decomposition temperature of 3a was lower than that of 1a. This means that calixarenes containing TMSE groups $\mathbf{3 a}, \mathbf{3} \mathbf{c}$ and $\mathbf{3 d}$ did not produce corresponding calixarenes such as 1a, 1c and 1d just by thermal treatment at the elevated temperature. As summarized in Table I, calixarenes containing TMSE groups 3a, 3c and 3d had higher decomposition temperatures than calixarene containing pendant $t$-BOC groups 2a, 2c and 2d. Furthermore, it is found that calixarene derivatives containing $\mathrm{CHE}$ groups had similar deprotection temperatures to calixarene derivatives containing $t$-BOC groups. 

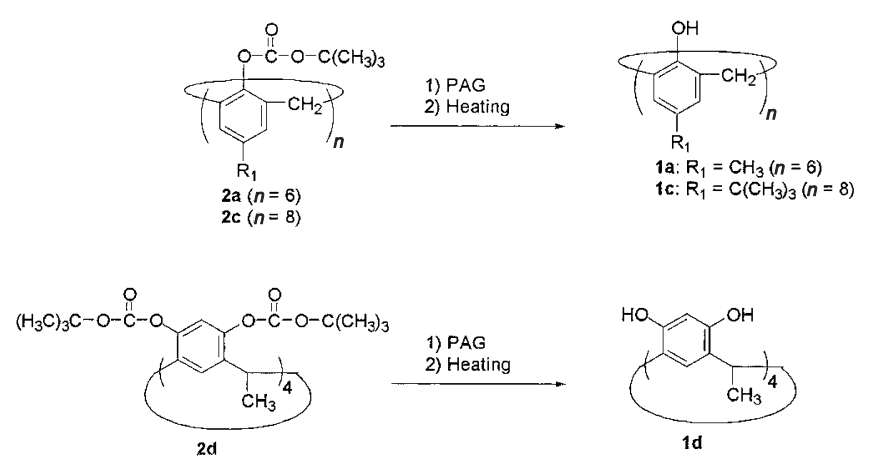

Scheme 3.

\section{Photoinduced Deprotection of Calixarenes Containing Protective Groups}

The photoinduced deprotection of calixarene $\mathbf{2 d}$ containing $t$-BOC groups was examined using bis-[4(diphenylsulfonio)phenyl]sulfide bis(hexafluorophosphate) (DPSP) as a PAG upon photoirradiation with a $250-\mathrm{W}$ high-pressure mercury lamp followed by heating at appropriate temperatures in the film state (Scheme 3).

The conversion of the $t$-BOC groups in the calixarene 2d was estimated from the decrease of the absorption peaks due to $\mathrm{C}=\mathrm{O}$ stretching at $1759 \mathrm{~cm}^{-1}$ in the IR spectra. The deprotection of the pendant $t$-BOC groups in 2d with $5 \mathrm{~mol} \%$ of DPSP was not found upon only photoirradiation in the film state. However, each reaction occurred smoothly, when the reaction of $\mathbf{2 d}$ was carried out with $5 \mathrm{~mol} \%$ of DPSP upon photoirradiation followed by heating for $30 \mathrm{~min}$ at certain temperatures such as 100,120 , and $150^{\circ} \mathrm{C}$. The deprotection rate increased with increasing the heating temperature, and the degree of deprotection of the $t$-BOC groups reached about $95 \%$ upon only $10 \mathrm{~s}$ of irradiation and heating at $150{ }^{\circ} \mathrm{C}$ for $30 \mathrm{~min}$.

The deprotection rate of the $t$-BOC groups in $\mathbf{2 d}$ was also affected by the DPSP concentration and the irradiation time, when the thermal treatment of $\mathbf{2 d}$ was carried out at $150^{\circ} \mathrm{C}$. As shown in Figure 3, the deprotection rate of the $t$-BOC groups increased with irradiation time. Then, the deprotection of $t$-BOC groups occurred almost quantitatively by heating them at $150^{\circ} \mathrm{C}$ for $30 \mathrm{~min}$, when the photoirradiation using $5 \mathrm{~mol} \%$ of DPSP was carried out for $60 \mathrm{~s}$.

The photoinduced deprotection of calixarenes $\mathbf{3 a}, \mathbf{3 c}$, and 3d containing TMSE groups with DPSP was also examined. The deprotection of $\mathbf{3 d}$ was not confirmed in the film state, because a film of $\mathbf{3 d}$ with good transparency could not be prepared by casting from a solution. The deprotection of TMSE groups in 3a and 3c with $5 \mathrm{~mol} \%$ of DPSP was carried out in the film state upon photoirradiation with UV-light followed by

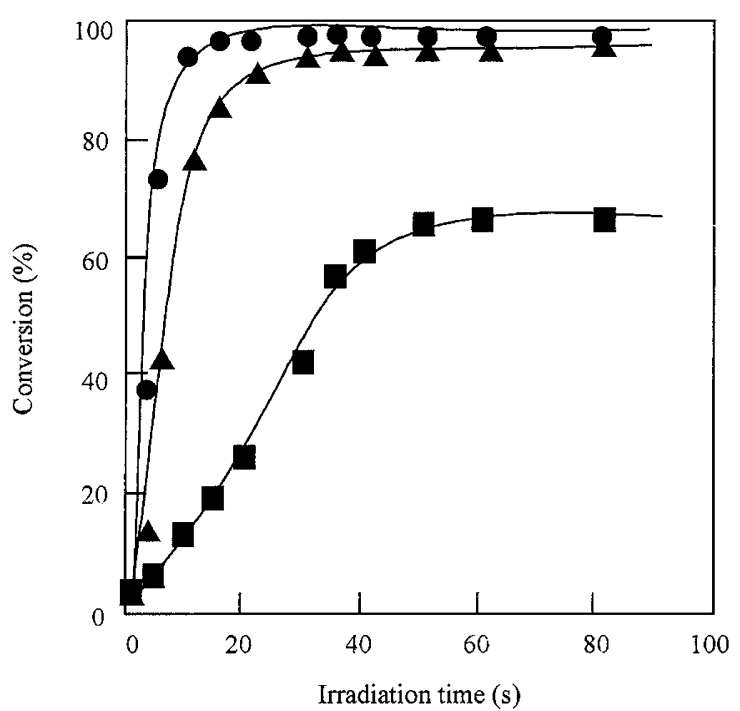

Figure 3. Effect of DPSP concentration and irradiation time on the photoinduced deprotection of the $t$-BOC groups of calixarene 2d. The heating was performed at $150{ }^{\circ} \mathrm{C}$ for $30 \mathrm{~min}$ : (O) with $5 \mathrm{~mol} \%$ of DPSP, $(\boldsymbol{\Delta})$ with $1 \mathrm{~mol} \%$ of DPSP, and ( $\boldsymbol{\square})$ with $0.2 \mathrm{~mol} \%$ of DPSP.

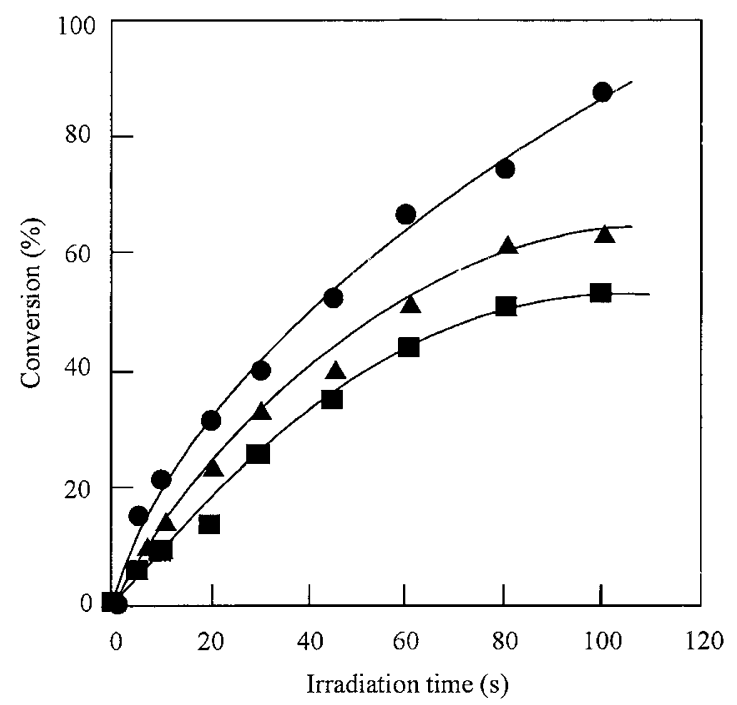

Figure 4. Effect of the heating temperature on the photoinduced deprotection of the CHE groups of calixarene $4 \mathbf{d}$ by using photoirradiation for $100 \mathrm{~s}$ with $5 \mathrm{~mol} \%$ of DPSP. The heating was performed for $30 \mathrm{~min}$ : $(\circlearrowleft)$ heated at $150^{\circ} \mathrm{C},(\boldsymbol{\Delta})$ heated at $120^{\circ} \mathrm{C}$, and $(\mathbf{\square})$ heated at $100^{\circ} \mathrm{C}$.

heating at $150{ }^{\circ} \mathrm{C}$ for $30 \mathrm{~min}$. The conversions of both TMSE groups of $\mathbf{3 a}$ and $\mathbf{3 c}$ were about only $20 \%$ upon irradiation for $300 \mathrm{~s}$. This result means that the deprotection rate of TMSE groups of calixarenes $\mathbf{3 a}$ and $\mathbf{3 c}$ was slower than those of $t$-BOC groups in calixarenes 2a and $2 \mathbf{c}$ under the same treatment conditions. It seems that some moisture was needed for effective photoinduced deprotection of the TMSE groups of the calixarene films as in the case of the deprotection of poly[4-(trimethylsilyloxy)styrene]. ${ }^{36}$

The photoinduced deprotection of calixarenes $4 \mathbf{a}, \mathbf{4 c}$, 
Table II. Various calixarenes and calixarene (meth)acrylates

\begin{tabular}{cccccc}
\hline Calixarene & $\mathrm{R}$ & $\mathrm{X}$ & Appearance & Yield $(\%)$ & IDT $\left({ }^{\circ} \mathrm{C}\right)^{\mathrm{a}}$ \\
\hline $\mathbf{1 a}$ & $\mathrm{Me}$ & $\mathrm{H}$ & Solid & 84 & 345 \\
$\mathbf{1 b}$ & $t$ - $\mathrm{Hu}$ & Solid & 90 & 348 \\
$\mathbf{5 a}$ & $\mathrm{Me}$ & $-\mathrm{CO}-\mathrm{CH}=\mathrm{CH}_{2}$ & Solid & 93 & 434 \\
$\mathbf{5 b}$ & $t-\mathrm{Bu}$ & $-\mathrm{CO}-\mathrm{CH}=\mathrm{CH}_{2}$ & Solid & 85 & 406 \\
$\mathbf{6 a}$ & $\mathrm{Me}$ & $\left.-\mathrm{CO}-\mathrm{C}(\mathrm{CH})_{3}\right)=\mathrm{CH}_{2}$ & Solid & 85 & 392 \\
$\mathbf{6 b}$ & $t-\mathrm{Bu}$ & $-\mathrm{CO}-\mathrm{C}\left(\mathrm{CH}_{3}\right)=\mathrm{CH}_{2}$ & Solid & 74 & 381 \\
$\mathbf{7 a}$ & $\mathrm{Me}$ & $-\mathrm{CH}_{2} \mathrm{CH}(\mathrm{OH}) \mathrm{CH}_{2}-\mathrm{O}-\mathrm{CO}-\mathrm{C}\left(\mathrm{CH}_{3}\right)=\mathrm{CH}_{2}$ & Solid & 86 & 372 \\
$\mathbf{8 a}$ & $\mathrm{Me}$ & $-\mathrm{CO}-\mathrm{NH}-\mathrm{CH}_{2} \mathrm{CH}_{2}-\mathrm{O}-\mathrm{CO}-\mathrm{C}\left(\mathrm{CH}_{3}\right)=\mathrm{CH}_{2}$ & Solid & 77 & 247 \\
$\mathbf{8 b}$ & $\mathrm{Me}$ & $-\mathrm{CO}-\mathrm{NH}-\mathrm{CH}_{2} \mathrm{CH}_{2}-\mathrm{O}-\mathrm{CO}-\mathrm{C}\left(\mathrm{CH}_{3}\right)=\mathrm{CH}_{2}$ & Solid & 80 & 232 \\
$\mathbf{9 a}$ & $\mathrm{Me}$ & $-\left(\mathrm{CH} \mathrm{CH}_{2} \mathrm{O}\right)_{n}-\mathrm{CO}-\mathrm{CH}=\mathrm{CH}{ }_{2}(n=2.5)$ & Liquid & 84 & 382 \\
\hline
\end{tabular}

${ }^{\mathrm{a}}$ Initial decomposition temperature.

and 4d containing CHE groups with $5 \mathrm{~mol} \%$ of DPSP were also enhanced by heating after the UV irradiation. As shown in Figure 4, the deprotection rate increased with irradiation time and heating temperature, and the conversions of the CHE groups of $\mathbf{4 d}$ were about 87, 64 , and $53 \%$ upon photoirradiation for $100 \mathrm{~s}$ followed by heating for $30 \mathrm{~min}$ at 150,120 , and $100^{\circ} \mathrm{C}$, respectively.

From these results on the photo-induced deprotection of the certain protective groups, such as $t$-BOC, TMSE and CHE in the calixarene derivatives, it was found that the pendant $t$-BOC groups in calixarenes had the highest deprotection rate. As the substrate of the protecting groups, $C$-methylcalix[4]resorcinarene was found to be better matrix than $p$-methylcalix[6]arene and $p$ tert-butylcalix[8]arene from the viewpoint of the deprotection rate of the aforementioned protective groups.

\section{SYNTHESIS AND CHARACTERIZATION OF CALIXARENES CONTAINING POLYMERIZABLE GROUPS}

\section{Calixarenes Containing (Meth)acryloyl Groups ${ }^{11}$}

Polyfunctional (meth)acrylates with calixarene backbones [calixarene (meth)acrylates], $p$-methylcalix[6]arene containing acryloyl group 5a, $p$-tert-butylcalix[6]arene containing acryloyl group $\mathbf{5 b}, p$-methylcalix[6]arene $\mathbf{6 a}$, and $p$-tert-butylcalix[6]arene $\mathbf{6 b}$ were synthesized with good yields by the condensation reaction of $p$-methylcalix[6]arene $\mathbf{1 a}$ and $p$-tertbutylcalix[6]arene 1b with acryloyl chloride (AC) or methacryloyl chloride (MAC) using triethylamine as $\mathrm{HCl}$ acceptor, respectively (Scheme 4 and Table II).

$p$-Methylcalix[6]arene containing methacrylate groups $7 \mathbf{a}$ was obtained with $86 \%$ yield by the addition reaction of 1a with glycidyl methacrylate (GMA) in the presence of TBAB as a catalyst. Calix[6]arenes containing methacryloyl group $\mathbf{8 a}$ and $\mathbf{8 b}$ were prepared by the addition reaction of $\mathbf{1 a}$ and $\mathbf{1 b}$ with 2-(methacryloyloxy)ethylisocyanate (MOI) in the

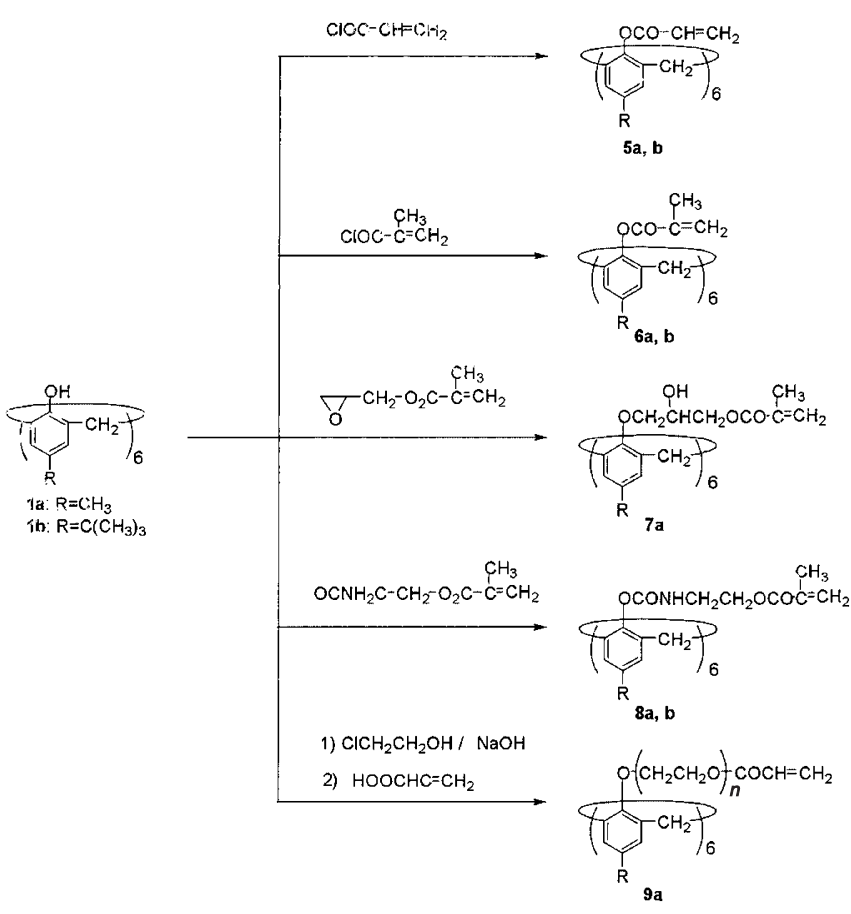

Scheme 4.

presence of dibutyltin dilaulate as a catalyst. The precursor of calixarene (6a) was synthesized by the condensation reaction of $\mathbf{1 a}$ with 2-chloroethanol using sodium hydroxide and TBAB. The hydroxyl value of the ethoxylated product $(244 \mathrm{mg} ; \mathrm{KOH} / \mathrm{g})$ indicates that average ethoxylation for each phenolic hydroxyl group of 1a is 2.5. p-Methylcalix[6]arene with acryloyloxy(oligo(oxyethylene)) 9a was also synthesized by the condensation reaction of this precursor with acrylic acid using $p$-toluenesulfonic acid.

All of the calixarene (meth)acrylates excepting 9a were solid at room temperature. The obtained $p$ alkylcalixarene derivatives containing polyfunctional (meth)acrylate groups were well confirmed by IR and ${ }^{1} \mathrm{H}$ NMR spectra.

All calixarene acrylates were soluble in such solvents as acetone, ethyl acetate, chloroform, dichloromethane, 1,4-dioxane, DMF, and NMP. Calixarene acrylate 9a 
was also soluble in methanol and toluene at room temperature.

Thermogravimetric analysis (TGA) of the starting $p$-alkylcalixarenes and the resulting calixarene (meth)acrylates was examined under nitrogen to confirm their thermal stability. The initial decomposition temperatures (IDTs) of $\mathbf{1 a}$ and $\mathbf{1 b}$ were 345 and $348^{\circ} \mathrm{C}$, respectively. On the other hand, IDTs of calixarene acrylates $\mathbf{5 a}$ and $\mathbf{5 b}$ were 434 and $406^{\circ} \mathrm{C}$, respectively, as shown in Figure 5.

This means that calixarene acrylates $\mathbf{5 a}$ and $\mathbf{5 b}$ had very high thermal stability as polyfunctional (meth)acrylate oligomers, although the IDT of $\mathbf{5 b}$ was lower than that of $\mathbf{5 a}$ due to the decomposition of $p$-tertbutyl groups on the calixarene residue. IDT data of the other calixarene (meth)acrylate are also summarized in Table II.

The IDTs of calixarene methacrylates $\mathbf{6 a}$ and $\mathbf{6 b}$ were 392 and $381{ }^{\circ} \mathrm{C}$, respectively. This result suggests that $p$-alkylcalixarene acrylates $\mathbf{5 a}$ and $\mathbf{5 b}$ have higher thermal stability than $p$-alkylcalixarene methacrylates 6a and $\mathbf{6 b}$ possibly due to effective radical polymerization of acrylate groups of $\mathbf{5 a}$ and $\mathbf{5 b}$. That is, a thermal crosslinking reaction of calixarene derivatives enhanced effectively their thermal stability, because calixarene (meth)acrylates $\mathbf{5 a}, \mathbf{5 b}, \mathbf{6 a}$ and $\mathbf{3 b}$ showed

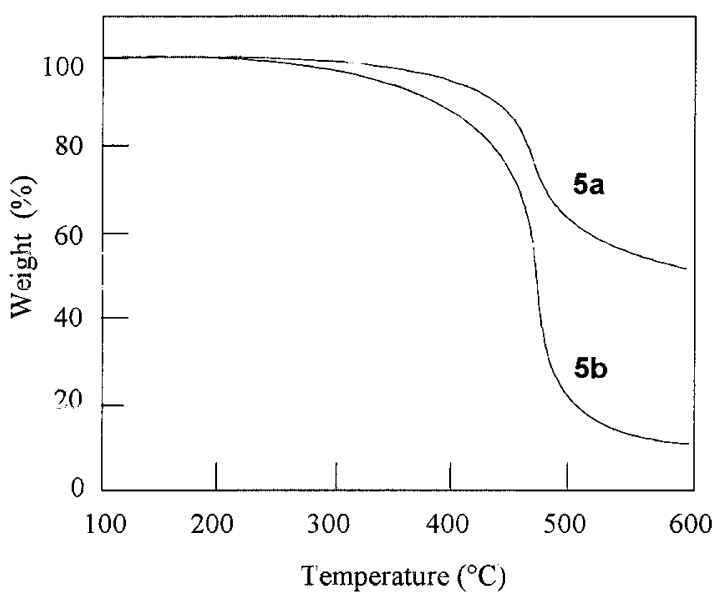

Figure 5. TGA curve of $\mathbf{5 a}$ and $\mathbf{5 b}$ at a heating rate of $10^{\circ} \mathrm{C} \mathrm{min}^{-1}$ under nitrogen atmosphere. much higher thermal stability than calixarenes 1a and $\mathbf{1 b}$ did. The IDTs of 9a and 7a were lower than those of $5 \mathbf{a}$ and $\mathbf{6 a}$. It seems that the thermal stability of calixarene (meth)acrylates decreased with the introduction of spacer chain between calixarene backbones and (meth)acrylate groups. The IDTs of $\mathbf{8 a}$ and $\mathbf{8 b}$ were much lower than those of $\mathbf{5 a}$ and $\mathbf{5 b}$. It seems that urethane linkages between calixarene backbones and methacrylate groups were ascribable to lower IDTs of $\mathbf{8 a}$ and $\mathbf{8 b}$ than other calixarene derivatives such as $\mathbf{5 a}$ and $\mathbf{5 b}$.

\section{Calixarenes Containing Cationically Polymerizable Groups $^{10}$}

Calixarene containing cationically polymerizable groups such as propargyl, allyl, and vinyl ether groups were prepared by the substitution reactions of 1a or 1c with certain unsaturated alkyl halides, propargyl bromide (PB), allyl bromide (AB), and 2-chloroethyl vinyl bromide (CEVE) using $\mathrm{KOH}$ or $\mathrm{NaH}$ and $\mathrm{TBAB}$ (Scheme 5). The substitution reactions proceeded smoothly with $100 \%$ degree of substitution to give the targeted calixarene derivatives with good isolated yields. These results mean that $p$-alkylcalixarenes such as 1a and 1c can be modified easily to form new functional calixarene derivatives by the substitution reaction of potassium or sodium salts of $\mathbf{1 a}$ or $1 \mathbf{c}$ with appropriate alkyl halides using phase-transfer catalysis under mild reaction conditions.

The isomerization of calixarene 11a containing allyl ether groups was carried out using tert-BuOK in NMP at $80^{\circ} \mathrm{C}$ according to the reported method by Crivello et al. ${ }^{27,28}$ The reaction proceeded quantitatively under this reaction condition, and the corresponding calixarene 13a containing $100 \mathrm{~mol} \%$ of $Z$-1-propenyl ether groups, which was confirmed by ${ }^{1} \mathrm{H}$ NMR spectrum, was obtained in $80 \%$ yield (Scheme 6).

$p$-Methylcalix[6]arene containing hydroxyalkyl vinyl ether groups 14a was also prepared by the addition reaction of $\mathbf{1 a}$ with glycidyl vinyl ether (GVE) in NMP at $110^{\circ} \mathrm{C}$ for $48 \mathrm{~h}$ (Scheme 7).

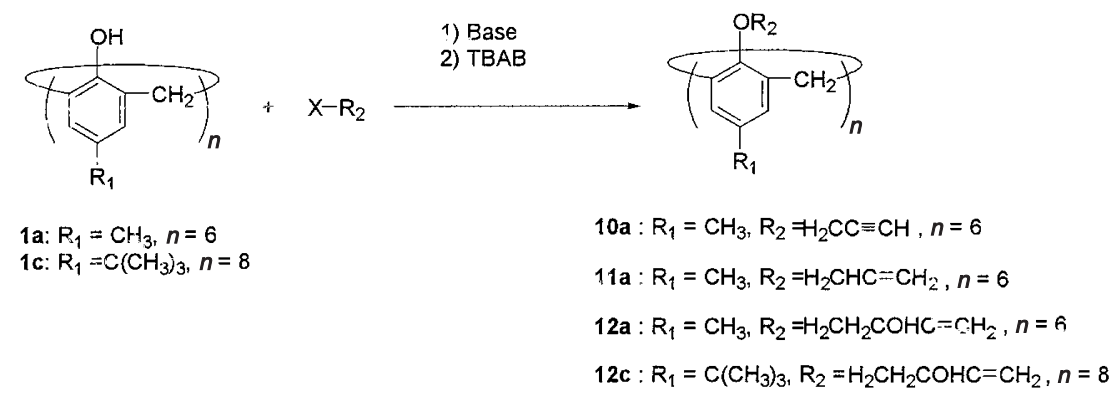

Scheme 5. 


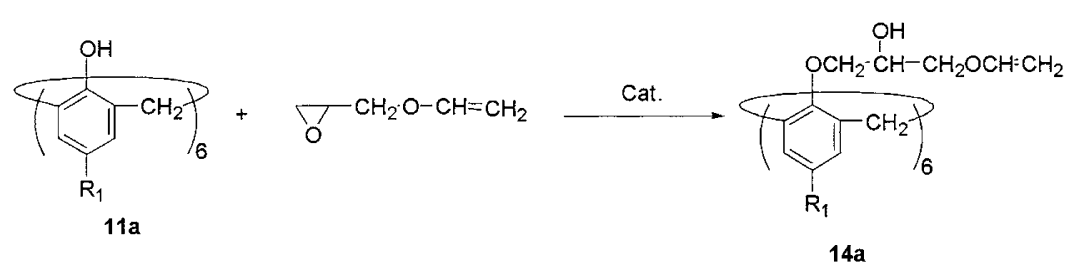

Scheme 7.

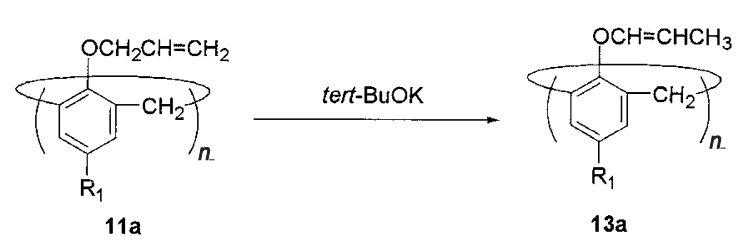

Scheme 6.

Table III. UV spectra and thermal properties of calixarene derivatives

\begin{tabular}{cccc}
\hline Calixarene & $\begin{array}{c}\lambda \max ^{\mathrm{a}} \\
(\mathrm{nm})\end{array}$ & $\begin{array}{c}T_{\mathrm{g}}^{\mathrm{b}} \\
\left({ }^{\circ} \mathrm{C}\right)\end{array}$ & $\begin{array}{c}T_{\mathrm{d}}{ }^{10 \% \mathrm{c}} \\
\left({ }^{\circ} \mathrm{C}\right)\end{array}$ \\
\hline 10a & 280 & 314 & 412 \\
11a & 272 & 203 & 363 \\
12a & 280 & 245 & 371 \\
12c & 279 & 177 & 378 \\
13a & 280 & 226 & 349 \\
14a & 280 & 148 & 374 \\
\hline
\end{tabular}

${ }^{\mathrm{a}}$ Measured at film state. ${ }^{\mathrm{b}} T_{\mathrm{g}}$ : Glass transition temperature. ${ }^{\mathrm{c}} T_{\mathrm{d}}{ }^{10 \%}$ : The temperature at $10 \%$ loss of mass.

$T_{\mathrm{g}} \mathrm{s}$ of calixarene derivatives $\mathbf{1 0 a}-\mathbf{1 4 a}$ are summarized in Table III. This result shows that the calixarene derivatives 10a-14a containing cationically reactive groups have high $T_{\mathrm{g}}$ values, which is an important characteristic of photo-curable oligomers. The temperature at $10 \%$ loss of mass $\left(T_{\mathrm{d}}{ }^{10 \%}\right)$ of calixarene derivatives 10a-14a excepting calixarene 10a showed higher temperature than $350^{\circ} \mathrm{C}$. This means that these calixarene derivatives have excellent thermal stability as photocurable oligomers.

All calixarenes 10a-14a were insoluble in water, cyclohexane, and acetonitrile, however, they were soluble in ethyl acetate, chloroform, dichloromethane, toluene, and 1,4-dioxane, as well as THF, DMF, DMAc, NMP, and DMSO

\section{Calixarenes Containing Cyclic Ether Groups ${ }^{37,38}$}

Synthesis of $p$-methylcalix[6]arene containing oxirane groups 15a by the substitution reaction of $1 \mathbf{a}$ with equivalent amount of epibromohydrin (EBH) was examined using bases such as pyridine, triethylamine, $\mathrm{DBU}, \mathrm{KOH}$, or $\mathrm{NaOH}$ in $\mathrm{MNP}$ at $50{ }^{\circ} \mathrm{C}$ for $12 \mathrm{~h}$, however, no soluble products were obtained. It seems that the anionic ring-opening polymerization of EBH or oxirane groups introduced in 1a might have occurred as a side reaction during the reaction. On the other

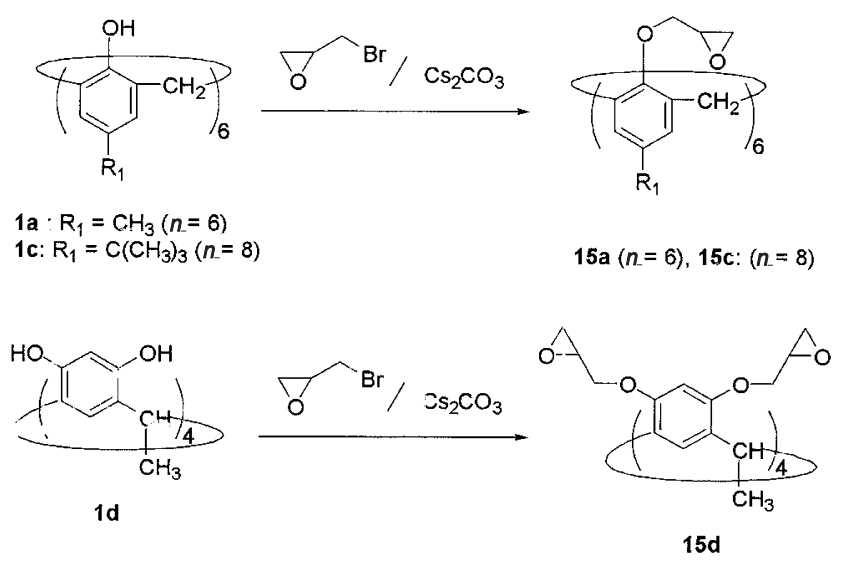

Scheme 8.

hand, when the reactions using weak inorganic bases such as $\mathrm{Na}_{2} \mathrm{CO}_{3}, \mathrm{~K}_{2} \mathrm{CO}_{3}$, or $\mathrm{Cs}_{2} \mathrm{CO}_{3}$ under the same conditions, soluble products were produced. The targeted $p$-methylcalix[6]arene derivative $15 a$ was successfully prepared with $88 \%$ yield from the reaction of 1a with 1.2 times amount of EBH and 1.2 times amount of $\mathrm{Cs}_{2} \mathrm{CO}_{3}$ at $50^{\circ} \mathrm{C}$ for $48 \mathrm{~h}$. Based on the above reaction conditions, $p$-tert-butylcalix[8]arene containing oxirane groups $15 \mathrm{c}$ and $C$-methylcalix[4]resorcinarene containing oxirane groups 15d were also prepared with good yields (Scheme 8). These results show that cesium carbonate is a suitable base for the substitution reaction of calixarenes with EBH to synthesize calixarene derivatives containing oxirane groups. The synthesized calixarenes containing oxirane groups were well confirmed by IR and ${ }^{1} \mathrm{H}$ NMR spectra, and elemental analysis.

It is well known that oxetane groups have high reactivity on cationic polymerization with certain cationic initiators. We designed new polyfunctional oxetane oligomers with calixarene backbones as new materials for photoinitiated cationic curing system. (3-Methyloxetan-3-yl)methyl-4-toluenesulfonate (MOMT) and (3-ethyloxetanyl-3-yl)methyl-4-toluenesulfonate (EOMT), as starting materials for the synthesis of calixarenes containing oxetane groups, were synthesized by the reaction of $p$-toluenesulfonyl chloride with 3-hydroxymethyl-3-methyloxetane and 3-hydroxymethyl3-ethyloxetane, respectively (Scheme 9). Substitution reactions of calixarenes 1a, 1c, and 1d with MOMT or EOMT were performed using $\mathrm{KOH}$ and TBAB, be- 


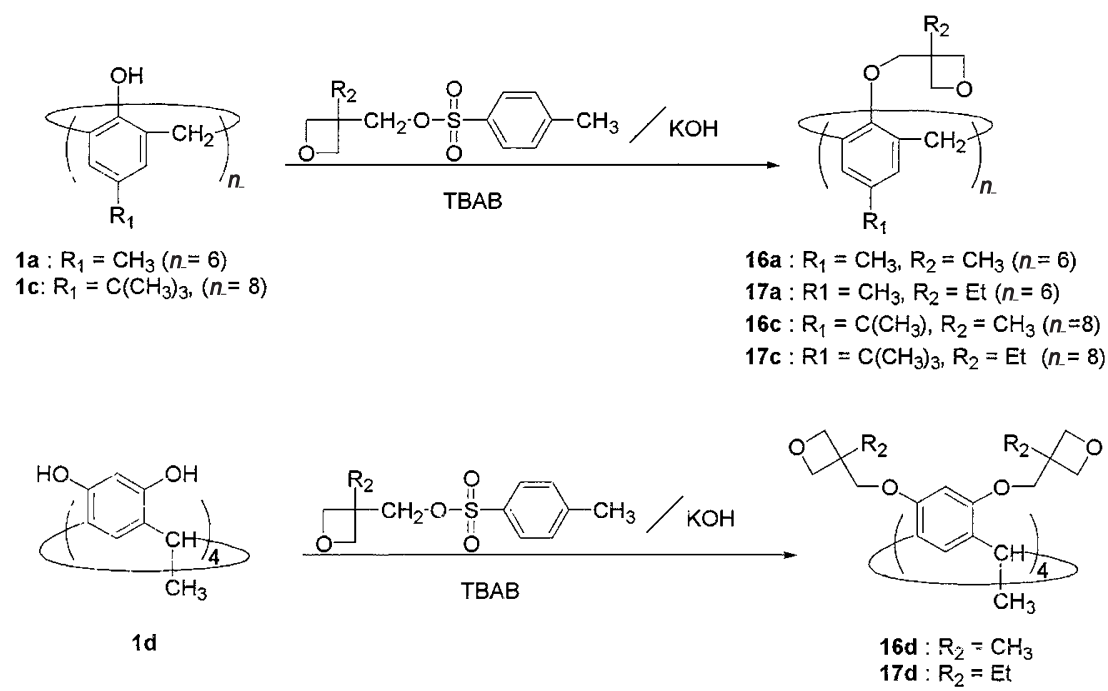

Scheme 9.
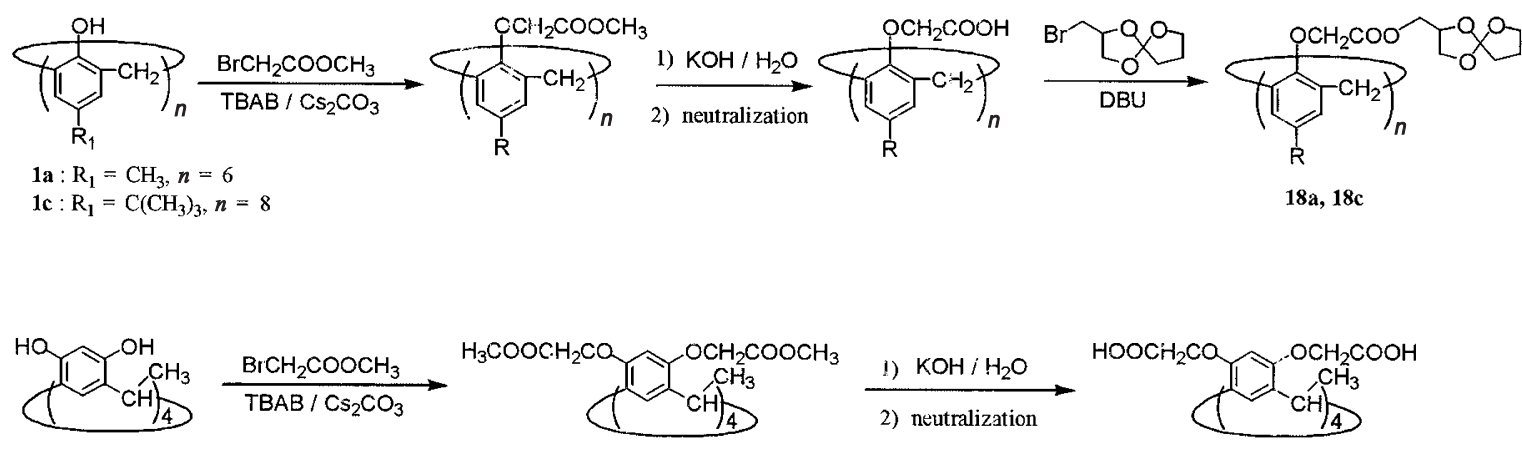

1d

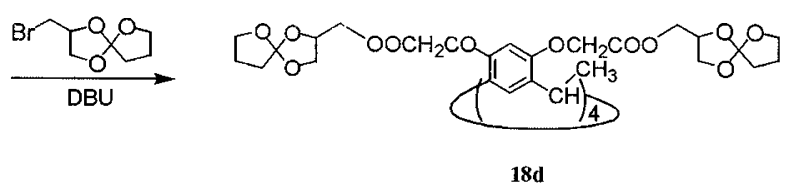

Scheme 10.

cause it is well known ${ }^{39}$ that substitution reactions of alcohol and phenol with tosylate or sulfonate proceed smoothly to give the corresponding ethers in the presence of inorganic strong bases and phase transfer catalysts under mild reaction conditions. Calixarenes containing 3-methyloxetane groups $\mathbf{1 6 a}, \mathbf{1 6 c}$, and $\mathbf{1 6 d}$ with $100 \%$ degree of substitution were obtained in good yields by the reaction of $\mathbf{1 a}, \mathbf{1 c}$, and $\mathbf{1 d}$ with slightly excess amount of MOMT at $70^{\circ} \mathrm{C}$ for $24 \mathrm{~h}$ in NMP. Calixarenes containing 3-ethyloxetane groups $17 \mathbf{a}, \mathbf{1 7} \mathbf{b}$, and $\mathbf{1 7} \mathbf{c}$ were also prepared by the reaction with EOMT under the same conditions as applied for the synthesis of calixarenes $\mathbf{1 6 a}$.

All of the synthesized calixarenes containing pendant oxetane groups were confirmed by IR and ${ }^{1} \mathrm{H} N M R$ spectra, and elemental analysis. These results mean that calixarenes such as $\mathbf{1 a}, \mathbf{1 c}$, and $\mathbf{1 d}$ can be modified easily to form new photo-functional calixarene derivatives by the substitution reaction of potassium salts of $\mathbf{1 a}$, 1c, and 1d with MOMT or EOMT using phase-transfer catalysis under relatively mild reaction conditions.

Synthesis of calixarene containing spiro ortho ester groups was attempted using the substitution reaction of 1 a with 2-bromomethyl-1,4,6-trioxaspiro[4.4]nonane (BMTSN) using $\mathrm{KOH}$ and TBAB, based on the substitution reaction of calixarenes with $\mathrm{EBH}$, however, no corresponding calixarene derivatives was obtained at all.

It is considered that direct introduction of spiro ortho ester groups into calixarene molecules by the reaction of BMTSN seemed to be very difficult to achieve due to both the steric hindrance of calixarene molecules and spiro ortho ester groups, and that the elimination reaction of BMTSN proceeded ${ }^{40}$ as a side reaction to give the corresponding 2-methylene-1,4,6trioxaspiro[4.4]nonane. Therefore, we examined the 
introduction of an appropriate spacer chain between calixarene molecules and spiro ortho ester groups as shown in Scheme 10.

The substitution reaction of $\mathbf{1 a}, \mathbf{1 c}$, and $\mathbf{1 d}$ with methyl $\alpha$-bromoacetate (MBA) was conducted using $\mathrm{Cs}_{2} \mathrm{CO}_{3}$ and TBAB in NMP at $70{ }^{\circ} \mathrm{C}$ for $48 \mathrm{~h}$, and corresponding calixarenes with spacer moieties were obtained in good yields. Then, the hydrolysis of the obtained calixarenes was performed using excess amount of $\mathrm{KOH}$ and TBAB in the mixed solvent of 1,4-dioxane and water to give calixarene derivatives with carboxymethoxy groups in good yields. Calixarenes containing spiro ortho ester groups 18a, 18c, and 18d were prepared in good yields by the substitution reaction of calixarene derivatives with carboxymethoxy groups with excess amount of BMTSN using 1,8-diazabicyclo[5.4.0]undec-7-ene (DBU) as a base in NMP. All of the synthesized calixarenes containing pendant spiro ortho ester groups were confirmed by IR and ${ }^{1} \mathrm{H}$ NMR spectra, and elemental analysis.

It is found that calixarene derivatives containing cyclic ether groups and spiro ortho ester groups have excellent thermal stability as new photo-functional materials. The temperatures $T_{\mathrm{d}}{ }^{5 \%}$ and $T_{\mathrm{d}}{ }^{10 \%}$ of all calixarene derivatives containing oxirane and oxetane groups recorded higher than $350^{\circ} \mathrm{C}$. The temperatures $T_{\mathrm{d}}{ }^{5 \%}$ and $T_{\mathrm{d}}{ }^{10 \%}$ of calixarenes derivatives containing spiro ortho ester groups were higher than $315^{\circ} \mathrm{C}$. Interestingly, calixarene derivatives with $C$-methylcalix[4]resorcinarene structures had higher thermal stability than the corresponding calixarene derivatives with $p$-methylcalix[6]arene or $p$-tertbutylcalixarene structures.

\section{PHOTOINITIATED POLYMERIZATION OF CALIXARENE DERIVATIVES}

\section{Photoinitiated Radical Polymerization of Calixarenes Containing (Meth)acryloyl Groups ${ }^{11}$}

The photoinitiated radical polymerizations of calixarene (meth)acrylates 5a, 6a, 7a, and 8a were carried out with $50 \mathrm{wt} \%$ of 2-phenoxyethyl acrylate (PEA) as a diluent, because these calixarene derivatives were solid at room temperature. Photoirradiation of the calixarene (meth)acrylates composites including $1 \mathrm{wt} \%$ of benzyl dimethyl ketal as a photoinitiator was performed using a high-pressure mercury lamp $\left(20 \mathrm{~mW} \mathrm{~cm}^{-2}\right)$ under nitrogen atmosphere or in air. As shown in Figure 6, the conversion of $\mathrm{C}=\mathrm{C}$ double bond of acrylate groups in 5a, which was estimated by IR spectrum, was higher than that of methacrylate groups in $\mathbf{6 a}$ under the same conditions.



Figure 6. Rate of photopolymerization of calixarene methacrylates diluted with PEA $(50 / 50, \mathrm{w} / \mathrm{w})$ in the presence of benzyldimethyl ketal $(1 \mathrm{wt} \%)$ under nitrogen atmosphere by using a high-pressure mercury lamp $\left(20 \mathrm{~mW} \mathrm{~cm}^{-2}\right.$ at $\left.360 \mathrm{~nm}\right)$. ( $) 5 \mathrm{a}$, ( 6a, (А) 7a, (О) 8a.

Table IV. Conversion of calixarene (meth)acrylates by photoirradiation

\begin{tabular}{cccc}
\hline Calixarene Conv.\% in $\mathrm{N}_{2}{ }^{\mathrm{a}}$ Conv.\% in air $^{\mathrm{b}}$ & Acryloyl eq. $\left(\mathrm{g} \mathrm{mol}^{-1}\right)^{\mathrm{c}}$ \\
\hline $\mathbf{5 a}$ & 97 & 68 & 174 \\
$\mathbf{6 a}$ & 77 & 60 & 188 \\
$7 \mathbf{a}$ & 90 & 61 & 262 \\
$\mathbf{8 a}$ & 91 & 74 & 275 \\
$\mathbf{9 a}$ & $80^{\mathrm{d}}$ & - & 284 \\
\hline
\end{tabular}

${ }^{\mathrm{a}}$ Conversion (\%) of calixarene (meth)acrylates diluted with PEA $(50 \% \mathrm{w} / \mathrm{w})$ in the presence of benzyl dimethyl ketal $(1 \mathrm{wt} \%)$ as photoinitiator upon irradiation for $2000 \mathrm{~mJ}$ by high-pressure mercury lamp under nitrogen atmosphere. ${ }^{b}$ Conversion (\%) of calixarene (meth)acrylates under the same irradiation conditions in the air. '(Meth)acryloyl equivalent of each calixarene (meth)acrylates. ${ }^{\mathrm{d}}$ Conversion (\%) of 9a without PEA under the same irradiation.

This result shows that acrylate groups bonded in the calixarenes had higher photochemical reactivity than methacrylate groups did. It is also showed that both conversion of acrylate groups in $\mathbf{5 a}$ and methacrylate groups in 6a under nitrogen atmosphere were much higher than those in the air (Table IV). The sequence of the degree of the conversion of methacrylate groups was $8 \mathbf{a}=7 \mathbf{a}>6 \mathbf{a}$ in nitrogen atmosphere, and $8 \mathbf{a}>7 \mathbf{a}=$ 6a in the air. This result indicates that the introduction of flexible alkyl spacer chain between calixarene backbone and methacryloyl groups enhanced the photochemical reactivity of methacrylate groups, although the introduction of alkyl spacer chain decreased the concentration of methacrylate groups. Moreover, 9a was easily polymerized without PEA and indicated relatively high conversion of acrylic double bond.

Photoinitiated Cationic Polymerization of Calixarenes 


\section{Containing Cationically Polymerizable Groups ${ }^{10}$}

The photoinitiated cationic polymerizations of calixarenes 10a, 12a, 12c, 13a, and 14a were examined using $5 \mathrm{~mol} \%$ of 4-morpholino-2,5-dibutoxybenzenediazonium hexafluorophosphate (MDBZ) or DPSP as a PAG in the film state using a $250 \mathrm{~W}$ high-pressure mercury lamp. As shown in Figure 7, when MDBZ was used, the rate of the photochemical reaction increased as following order, 10a $>12 a>12 \mathrm{c}>13 \mathrm{a}$ $>$ 14a. This result means that calixarenes 10a having 1-propenyl ether groups and calixarene 14a having hydroxyl alkyl vinyl ether groups did not proceed effectively using MDBZ. On the other hand, when DPSP

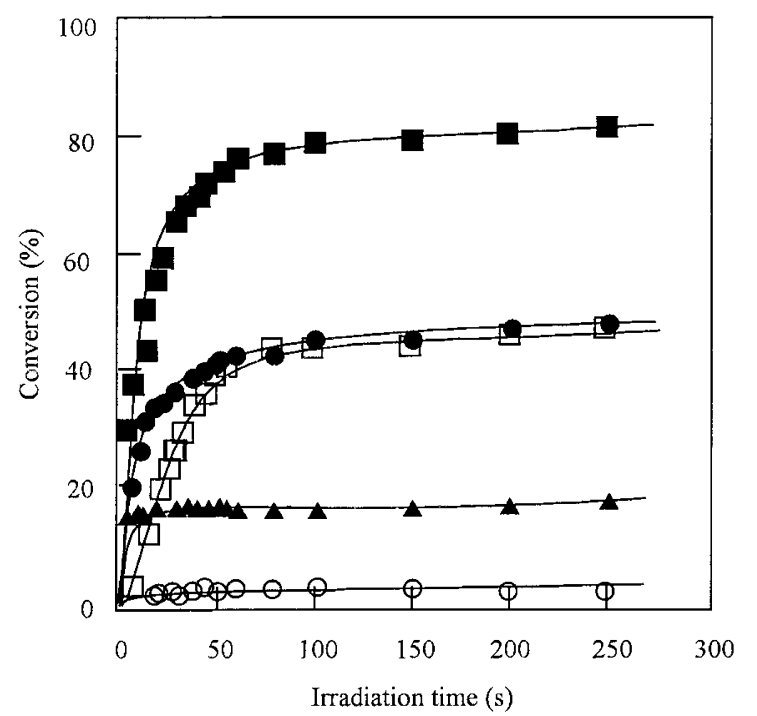

Figure 7. Rates of photopolymerization of calixarenes 10a,

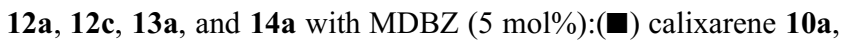
$(\square)$ calixarene 12c, $(\Delta)$ calixarene 13a, $(\bigcirc)$ calixarene 12a, $(\bigcirc)$ calixarene 14a.

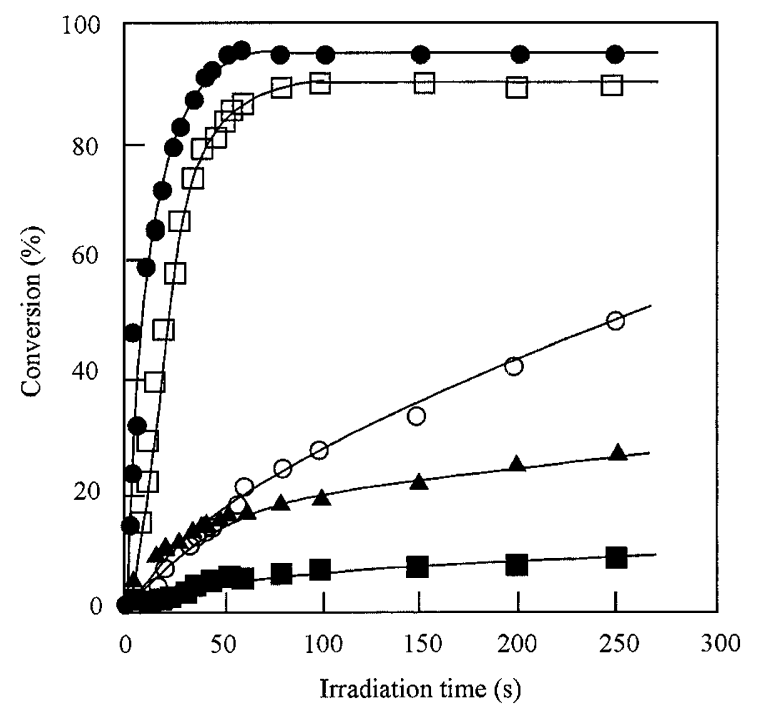

Figure 8. Rates of photochemical reaction of calixarenes 10a, 12a, 12c, 13a, and 14a with DPSP (5 mol\%): (ם) calixarene 10a, (๑) calixarene 12a, $(\square)$ calixarene 12c, $(\Delta)$ calixarene 13a, $(\bigcirc)$ calixarene 14a. was used, the rate of the photochemical reaction increased as following order, 12a $>12 \mathrm{c}>14 \mathrm{a}>13 \mathrm{a}>$ 10a (Figure 8). This result means that although DPSP has good activity as a PAG to the vinyl ether groups in the calixarenes, the photoinitiated cationic polymerization of calixarene 13a is strongly hindered by the hydroxyl groups in the molecule. It has been reported ${ }^{8}$ that the photoinitiated cationic polymerization of 1propenyl ether groups in liquid monomers proceeded very smoothly as did as the photoinitiated polymerization of vinyl ether groups. However, the photoinitiated cationic polymerization of 1-propenyl ether groups in calixarene 13a did not proceed smoothly. This may be due to the steric hindrance of calixarene structures or due to the inhibition of molecular motion of 1-propenyl ether groups bonded directly to the rigid calixarene backbone. From these results, it was found that combination with photo-acid generators is a very important factor for the photo-crosslinking reaction of calixarene derivatives containing certain cationically polymerizable groups, even though these calixarene derivatives have high photochemical reactivity.

\section{Photoinitiated Cationic Polymerization of Calixarenes} Containing Pendant Cyclic Ether Groups ${ }^{37,38}$

The photoinitiated cationic polymerizations of calixarenes $15 \mathbf{a}, 15 \mathbf{c}$, and $15 \mathbf{d}$ containing oxirane groups were examined using $5 \mathrm{~mol} \%$ of DPSP in the film state using a $250 \mathrm{~W}$ high-pressure mercury lamp. As shown in Figure 9, the rate of the reaction increased as following order, 15d $>15 \mathbf{a}>15 \mathbf{c}$, and the conversions of 15d, 15a, and $15 \mathbf{c}$ were reached 61 ,

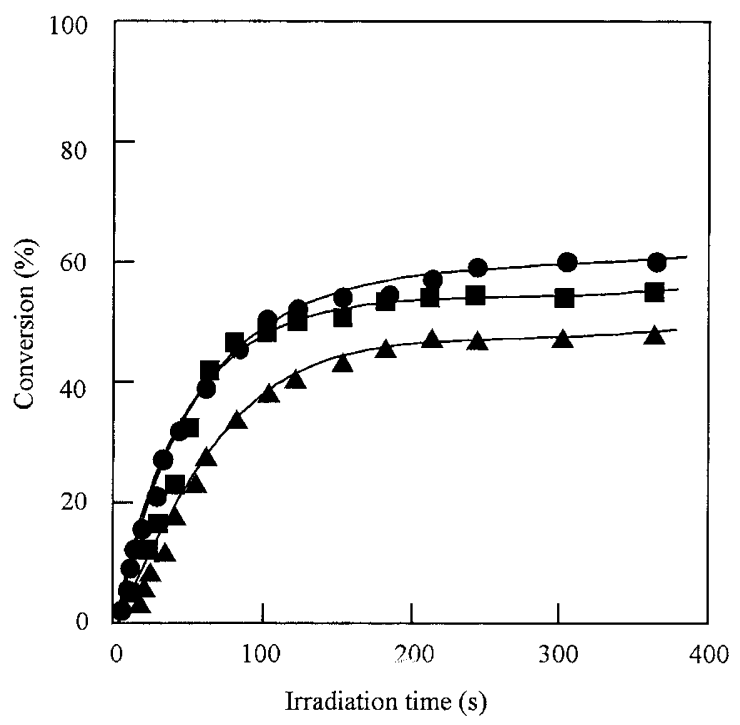

Figure 9. Rates of the photochemical reaction of calixarenes 15a, 15c, and 15d containing pendant oxirane groups with DPSP $(5 \mathrm{~mol} \%)$ : $(\circlearrowleft)$ calixarene $\mathbf{1 5 d},(\boldsymbol{\square})$ calixarene 15a, and $(\mathbf{\Lambda})$ calixarene $\mathbf{1 5 c}$. 


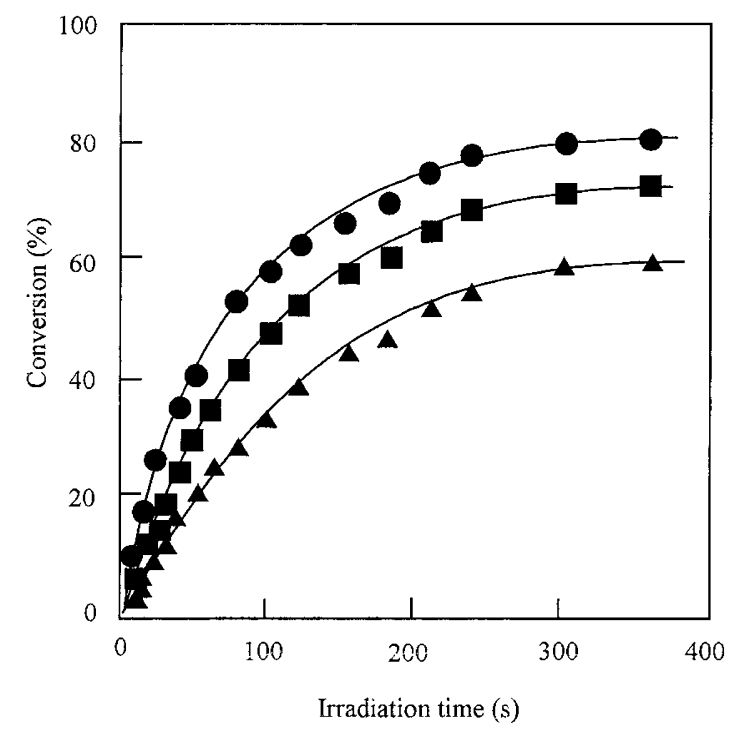

Figure 10. Rates of the photochemical reaction of calixarenes 16a, 16c, and 16d containing pendant (3-methyloxetane-3yl)methyl groups with DPSP (5 mol\%): () calixarene 16d, calixarene 16a, and $(\Delta)$ calixarene 16c.

55 , and $48 \mathrm{~mol} \%$ at $360 \mathrm{~s}$, respectively. This result showed the rate of the photoinitiated cationic polymerization of oxirane groups in calixarenes was affected by the structures of calixarene backbones, that is, $C$-methylcalix[4]resorcinarene derivative containing the oxirane groups (15d) had higher rate than those of $p$-methylcalix[6]arene derivative (15a) and $p$-tert-butylcalix[8]arene derivative (15c). The photoinitiated cationic polymerizations of calixarenes $\mathbf{1 5 a}$, 15c, and 15d were also performed with $5 \mathrm{~mol} \%$ of $(\eta$-cyclopentadiene)( $\eta$-1-isopropylbenzene)iron (CBI), and conversions of oxirane groups of, $15 \mathbf{a}, 15 \mathbf{c}$, and 15d were reached 25,33 , and $37 \mathrm{~mol} \%$ at $360 \mathrm{~s}$, respectively. These results mean that DPSP had higher activity than $\mathrm{CBI}$ on the photoinitiated cationic polymerization of calixarene derivatives containing oxirane groups in the film state.

The photoinitiated cationic polymerizations of calixarenes 16a, 16c, and 16d containing 3'-methyl-3'oxetanylmethoxy groups were also examined using $5 \mathrm{~mol} \%$ of DPSP under the same irradiation conditions. As shown in Figure 10, the reaction rate increased as following order, 16d $>16 \mathbf{a}>16 \mathbf{c}$, and the conversions of $16 \mathbf{d}, \mathbf{1 6 a}$, and $\mathbf{1 6 c}$ reached 81, 73, and $60 \mathrm{~mol} \%$ at $360 \mathrm{~s}$, respectively. This may be due to good mutual solubility between calixarene $\mathbf{1 6 d}$ and DPSP, or to higher concentration of the oxetane groups in the same cubic measures of the calixarene derivatives. From these examinations on the photoinitiated cationic polymerization, it was also proved that calixarene derivatives containing oxetane groups had higher photochemical reactivity than calixarene derivatives containing oxirane groups when DPSP or CBI was used.

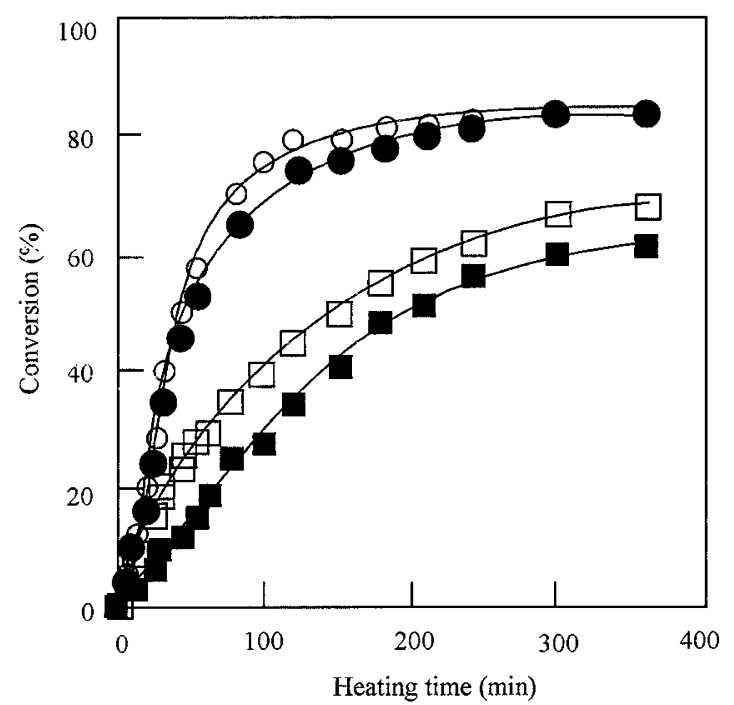

Figure 11. Rates of the cationic polymerization of calixarene 18d (containing spiro ortho ester groups) with DPSP (5 mol\%) upon UV irradation for $5 \mathrm{~min}$ followed by heating at $(\bigcirc) 170,(\bigcirc)$ $150,(\square) 120$, and (ם) $100{ }^{\circ} \mathrm{C}$.

The photoinitiated cationic polymerization of calixarenes containing spiro ortho ester groups was examined in the film state with $5 \mathrm{~mol} \%$ of certain photo-acid generators such as MDBZ, DPSP, and CBI upon UV irradiation using a $250 \mathrm{~W}$ high-pressure mercury lamp. The conversions of the spiro ortho ester groups were estimated from the decrease of the absorption peaks at $1050 \mathrm{~cm}^{-1}$ assignable to spiro ortho ester groups in the IR spectra.

Calixarene 18d films containing $5 \mathrm{~mol} \%$ of PAG did not show any decrease of the absorption peaks, when the photoirradiation of the polymer films was performed for $30 \mathrm{~min}$. Therefore, thermal treatment of the irradiated calixarene 18d films upon $5 \mathrm{~min}$ was examined by a heating at $150{ }^{\circ} \mathrm{C}$. When the photoinitiated cationic polymerization of calixarene $\mathbf{1 8 d}$ film was carried out with $5 \mathrm{~mol} \%$ of DPSP upon photoirradiation for $5 \mathrm{~min}$ followed by heating at certain temperatures such as $100,120,150$, and $170^{\circ} \mathrm{C}$, each reaction occurred smoothly. As shown in Figure 11, the reaction rate increased as with the heating temperature increased, and the conversion of the spiro ortho ester groups in $\mathbf{1 5 d}$ reached $83 \%$ by heating at $170^{\circ} \mathrm{C}$ for $360 \mathrm{~min}$.

The photoinitiated cationic polymerization of calixarenes 18a, 18c, and $18 \mathrm{~d}$ films containing spiro ortho ester groups was also performed with $5 \mathrm{~mol} \%$ of DPSP upon $5 \mathrm{~min}$ irradiation using a $250 \mathrm{~W}$ high-pressure mercury lamp. As shown in Figure 12, the rate of the reaction increased as following order, 18d $>18 \mathrm{a}>18 \mathrm{c}$, and the conversions of $\mathbf{1 8 d}, \mathbf{1 8 a}$, and $\mathbf{1 8 c}$ reached 84 , 72 , and $57 \mathrm{~mol} \%$ by heating at $360 \mathrm{~min}$, respectively. This may be due to good mutual solubility between cal- 


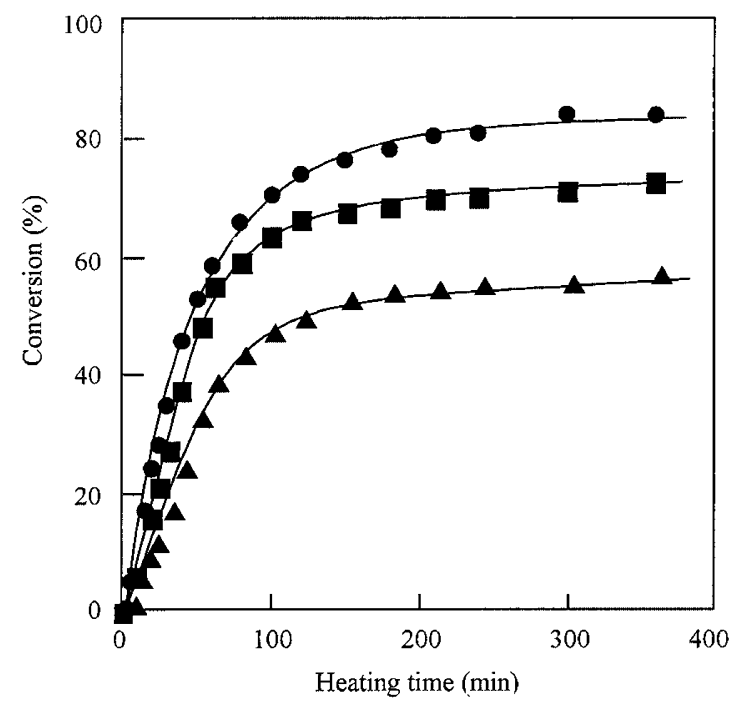

Figure 12. Rates of the cationic polymerization of calixarenes

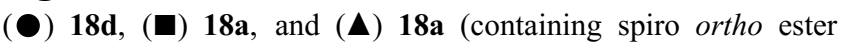
groups) with DPSP ( $5 \mathrm{~mol} \%$ ) upon UV irradiation for $5 \mathrm{~min}$ followed by heating at $150{ }^{\circ} \mathrm{C}$.

ixarene 18d and DPSP, or to higher concentration of the spiro ortho ester groups in the same cubic measures of the calixarene derivatives.

\section{THERMAL CURING REACTION OF EPOXY RESINS WITH CALIXARENES}

\section{Thermal Curing Reaction of Epoxy Resins with Cal- ixarenes $^{41}$}

The reaction behavior of thermal curing of epoxy resins with calixarenes using certain catalysts was examined in bulk. The conversions of the reaction could be monitored by decrease of the characteristic peak of oxirane groups at $910 \mathrm{~cm}^{-1}$ in FT-IR spectrum. The curing reaction of a commercially available epoxy resin, Epikote 828, with $p$-methylcalix[6]arene 1a (molar ratio of oxirane groups: $\mathrm{OH}$ groups $=1: 1$ ) was conducted using $4 \mathrm{~mol} \%$ of catalysts such as amines, potassium phenoxide/18-crown-6 complex (18-C-6/KOPh), and quaternary onium salts at $190^{\circ} \mathrm{C}$. Table V summarized conversions of oxirane groups of $\mathbf{1 a}$ at $10 \mathrm{~min}$ and $4 \mathrm{~h}$, and $T_{\mathrm{g}} \mathrm{s}$ of the resulting cured resins. The reaction was accelerated efficiently in initial stage by $N, N^{\prime}$-dimethylaminopyridine (DMAP) and DBU, and the conversions were 61 and $81 \%$ at 10 min and 93 and $93 \%$ at $4 \mathrm{~h}$, respectively. A crown ether complex, 18-C$6 / \mathrm{KOPh}$ and tetrabutylphosphonium bromide (TBPB), tetraphenylphosphonium bromide (TPPB) or chloride (TPPC) were also effective catalysts for the curing reaction, and the conversion reached over $95 \%$ at $4 \mathrm{~h}$. In all cases, $T_{\mathrm{g}} \mathrm{S}$ of the resulting materials were 194 $206^{\circ} \mathrm{C}$. It was found that tetrabutyl or tetraphophonium salts were suitable catalysts for the curing reaction of
Table V. Curing reaction of Epikote 828 with 1a using $4 \mathrm{~mol} \%$ of various catalysts at $190{ }^{\circ} \mathrm{C}$

\begin{tabular}{lccc}
\hline \multirow{2}{*}{ Catalysts } & \multicolumn{2}{c}{ Conversion $(\%)$} & \multirow{2}{*}{$\begin{array}{c}\mathrm{g}_{\mathrm{g}} \\
\left({ }^{\circ} \mathrm{C}\right)\end{array}$} \\
\cline { 2 - 3 } & at $10 \mathrm{~min}^{\mathrm{a}}$ & at $4 \mathrm{~h}^{\mathrm{b}}$ & 206 \\
TBPB & 25 & 95 & 195 \\
TPPB & 44 & 96 & 202 \\
TPPC & 32 & 96 & 206 \\
18-C-6/KOPh & 36 & 95 & 204 \\
TPP & 15 & 94 & 194 \\
DMAP & 61 & 93 & 197 \\
DBU & 81 & 93 & \\
\hline
\end{tabular}

${ }^{\text {a }}$ The conversion was given by thermal curing reaction of Epikote 828 with 1a using various catalysts at $190^{\circ} \mathrm{C}$ for $10 \mathrm{~min} .{ }^{\mathrm{b}}$ The conversion was given by thermal curing reaction of Epikote 828 with 1a using various catalysts at $190^{\circ} \mathrm{C}$ for $4 \mathrm{~h}$. ${ }^{\mathrm{c}}$ Measured by DSC at heating rate of $10^{\circ} \mathrm{C} \mathrm{min}^{-1}$ un$\operatorname{der} \mathrm{N}_{2}$.

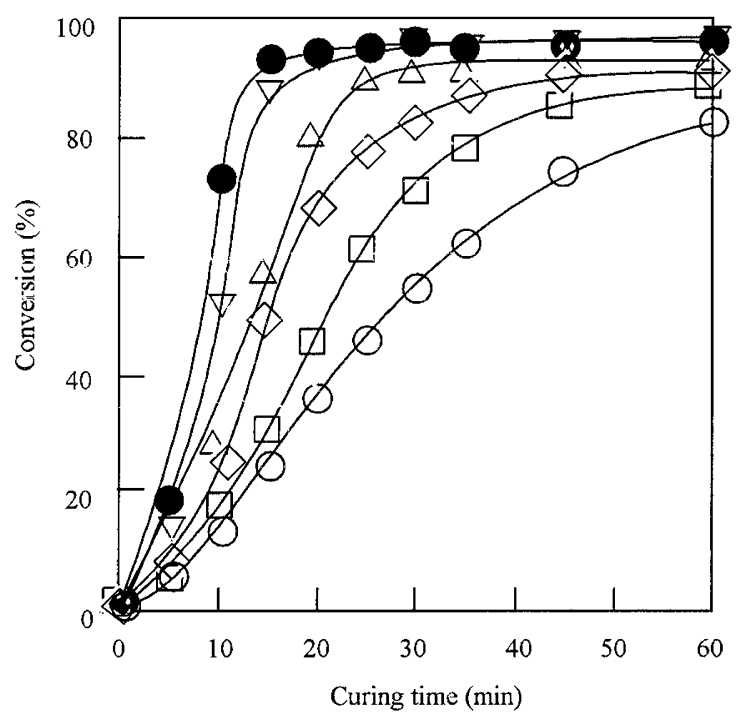

Figure 13. Curing reaction of Epikote 828 with 1a using 4 mol $\%$ of TBPB at various temperatures. $(\bigcirc) 170^{\circ} \mathrm{C}$, ( $\left.\square\right) 180^{\circ} \mathrm{C}$, $(\diamond) 190^{\circ} \mathrm{C},(\triangle) 200^{\circ} \mathrm{C},(\nabla) 210^{\circ} \mathrm{C},(\bullet) 220^{\circ} \mathrm{C}$.

Epikote 828 with 1a, considering catalytic activity, $T_{\mathrm{g}}$, and miscibility of the used catalysts.

Figure 13 shows the time-conversion curves of the curing reaction of Epikote 828 with 1a using 4 mol\% of TBPB at various temperatures. The reaction proceeded smoothly at high temperature, and the conversion reached $95 \%$ for $15 \mathrm{~min}$ at $220^{\circ} \mathrm{C}$.

In epoxy resin curing system, the relationships between conversions, degrees of crosslinking and $T_{\mathrm{g}} \mathrm{s}$ are very important factors to understand properties of the cured materials. The curing reaction of Epikote 828 with calixarene derivatives 1a, 1c, and $\mathbf{1 d}$ using $4 \mathrm{~mol} \%$ of TBPB was carried out at $190^{\circ} \mathrm{C}$ for $4 \mathrm{~h}$, and the conversions and $T_{\mathrm{g}} \mathrm{s}$ of the obtained resins were summarized in Table VI. The conversions of the reaction increased as following order, 1a $>1 \mathbf{1}>\mathbf{1 d}$. On the other hand, $T_{\mathrm{g}} \mathrm{S}$ of the obtained resins increased as following 
Table VI. Curing reaction of Epikote 828 with calixarenes, 1a, $1 \mathrm{c}$, and $1 \mathbf{d}^{\mathrm{a}}$

\begin{tabular}{cccc}
\hline Calixarene & Conversion $(\%)^{\mathrm{b}}$ & $T_{\mathrm{g}}\left({ }^{\circ} \mathrm{C}\right)^{\mathrm{c}}$ & $T_{\mathrm{d}}{ }^{10 \%}\left({ }^{\circ} \mathrm{C}\right)^{\mathrm{d}}$ \\
\hline 1a & 95 & 206 & 364 \\
1c & 87 & 188 & 365 \\
1d & 85 & 242 & 377 \\
\hline
\end{tabular}

${ }^{\text {a }}$ The curing reaction of Epikote 828 with calixarenes was carried out using $4 \mathrm{~mol} \%$ of TBPB at $190^{\circ} \mathrm{C}$ for $4 \mathrm{~h}$. ${ }^{\mathrm{b}}$ Measured by FT-IR spectrum. ${ }^{\mathrm{c}}$ Measured by DSC at heating rate of $10^{\circ} \mathrm{C} \mathrm{min}^{-1}$ under $\mathrm{N}_{2}$. ${ }^{\mathrm{d}}$ Measured by TGA at heating rate of $10^{\circ} \mathrm{C} \mathrm{min}^{-1}$ under $\mathrm{N}_{2}$.
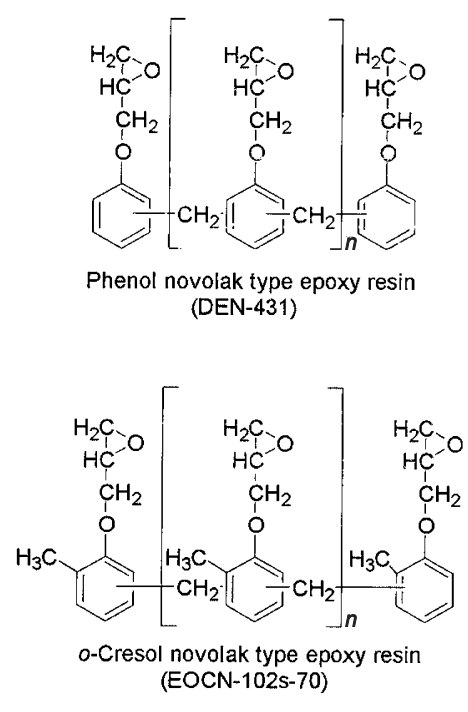

Scheme 11.

order, 1d $>$ 1a $>$ 1c. This means that the degree of crosslinking of the obtained resin with $\mathbf{1 d}$ is the highest degree, which would be due to the density of $\mathrm{OH}$ groups in the mixture of Epikote 828 and calixarenes used. It was also proved that the cured resins with the calixarenes had good thermal stability; the IDTs were over $360^{\circ} \mathrm{C}$ in nitrogen atmosphere.

Curing reaction of certain commercially available epoxy resins with 1a using $4 \mathrm{~mol} \%$ of TBPB was also examined at $200^{\circ} \mathrm{C}$ for $4 \mathrm{~h}$ (Scheme 11). The reaction of phenol novolak type epoxy resin DEN-431 or $o$ cresol novolak type resin EOCN-102s-70 with 1a proceeded with $95 \%$ and $86 \%$ conversion, respectively, and $T_{\mathrm{g}} \mathrm{s}$ of the cured resins were 203 and $214^{\circ} \mathrm{C}$ (Table VII). Thus, it was proved that the curing reaction of epoxy resins with calixarene 1a, 1c, and $\mathbf{1 d}$ using quaternary phosphonium salts proceeded efficiently high temperature $170-220^{\circ} \mathrm{C}$ to obtain cured resin with high $T_{\mathrm{g}} \mathrm{s}$ and good thermal stability.

Thermal Curing Reaction of Epoxy Resins with Calixarenes Containing Active Ester Groups ${ }^{42}$

The epoxy resins without hydroxyl groups are seemed to have low water-absorbing property in addition to high thermal property. Based on the regioselec-
Table VII. The cured resins of various epoxy resins with $\mathbf{1} \mathbf{a}^{\mathrm{a}}$

\begin{tabular}{lcc}
\hline \multicolumn{1}{c}{ Epoxy resin } & Conversion $(\%)^{\mathrm{b}}$ & $T_{\mathrm{g}}(\mathrm{oC})^{\mathrm{c}}$ \\
\hline DEN-431 & 95 & 203 \\
EOCN-102s-70 & 86 & 214 \\
Epikote828 & 95 & 209
\end{tabular}

${ }^{a}$ The curing reaction of various epoxy resins with 1a was carried out using $4 \mathrm{~mol} \%$ of TBPB at $200^{\circ} \mathrm{C}$ for $4 \mathrm{~h}$. ${ }^{\mathrm{b}}$ Measured by FT-IR spectrum. ${ }^{\mathrm{c}}$ Measured by DSC at heating rate of $10^{\circ} \mathrm{C} \mathrm{min}^{-1}$ under $\mathrm{N}_{2}$.

Table VIII. Thermal properties of the cured resin of Epikote828 with calixarenes containing ester groups ${ }^{\mathrm{a}}$

\begin{tabular}{ccccc}
\hline Calixarenes & Temp. $\left({ }^{\circ} \mathrm{C}\right)$ & Conv. $(\%)^{\mathrm{b}}$ & $T_{\mathrm{g}}\left({ }^{\circ} \mathrm{C}\right)^{\mathrm{c}}$ & $T_{\mathrm{d}}{ }^{10 \%}\left({ }^{\circ} \mathrm{C}\right)^{\mathrm{d}}$ \\
\hline 19a & 190 & 67 & 105 & 344 \\
& 200 & 73 & 113 & 345 \\
& 210 & 75 & 127 & 347 \\
& 220 & 82 & 135 & 347 \\
\hline 19c & 190 & 46 & 98 & 362 \\
& 200 & 55 & 107 & 363 \\
& 210 & 68 & 117 & 362 \\
& 220 & 47 & 114 & 364 \\
\hline 19d & 190 & 64 & 117 & 348 \\
& 200 & 65 & 124 & 347 \\
& 210 & 66 & 127 & 348 \\
& 220 & 69 & 134 & 347 \\
\hline 20a & 190 & 82 & 99 & 339 \\
& 200 & 85 & 107 & 337 \\
& 210 & 87 & 115 & 340 \\
& 220 & 91 & 124 & 343 \\
\hline 20c & 190 & 64 & 94 & 350 \\
& 200 & 67 & 106 & 351 \\
& 210 & 76 & 111 & 350 \\
& 220 & 73 & 108 & 349 \\
\hline
\end{tabular}

${ }^{\mathrm{a}}$ This cured resin was given by thermal curing reaction of Epikote 828 with calixarenes using $4 \mathrm{~mol} \%$ for $6 \mathrm{~h}$. ${ }^{\mathrm{b}}$ Measured by FT-IR spectrum. ${ }^{\mathrm{c}}$ Measured by DSC at heating rate of $10^{\circ} \mathrm{Cmin}^{-1}$ under $\mathrm{N}_{2}$. ${ }^{\mathrm{d}}$ Measured by TGA at heating rate of $10^{\circ} \mathrm{C} \mathrm{min}^{-1}$ under $\mathrm{N}_{2}$.

tive addition reaction of oxiranes ${ }^{43}$ with active carboxylic esters using quaternary onium salts catalysts, we designed calixarenes containing ester groups as new curing agents for epoxy resins without hydroxyl groups. Calixarenes containing methyl or phenyl ester groups were prepared in high yields by the reaction of the corresponding starting calixarenes with acetic anhydride or benzoyl chloride in the presence of pyridine. The curing reaction of Epikote 828 with $p$-methylcalix[6]arene containing methyl ester groups (19a), p-tert-butylcalix[8]arene containing methyl ester groups (19c), $C$-methylcalix[4]resorcinarene containing methyl ester groups (19d), $p$-methylcalix[6]arene containing phenyl ester groups (20a), and p-tertbutylcalix[8]arene containing phenyl ester groups (20c) using $4 \mathrm{~mol} \%$ of TPPB were examined at prescribed temperatures for $6 \mathrm{~h}$, and results were 
Table IX. Thermal properties of the cured resin of Epikote828 with mixed curing agents ${ }^{\mathrm{a}}$

\begin{tabular}{cccc}
\hline $\begin{array}{c}\text { Composition } \\
(\mathbf{1 9 d} / \mathbf{1 d})\end{array}$ & Conversion $(\%)^{\mathrm{b}}$ & $T_{\mathrm{g}}\left({ }^{\circ} \mathrm{C}\right)^{\mathrm{c}}$ & $T_{\mathrm{d}}{ }^{10 \%}\left({ }^{\circ} \mathrm{C}\right)^{\mathrm{d}}$ \\
\hline $100 / 0$ & 78 & 137 & 366 \\
$70 / 30$ & 85 & 170 & 362 \\
$50 / 50$ & 92 & 197 & 363 \\
$30 / 70$ & 94 & 217 & 364 \\
$0 / 100$ & 96 & 233 & 368 \\
\hline
\end{tabular}

${ }^{a}$ This cured resin was given by thermal curing reaction of Epikote 828 with mixed curing agents using $4 \mathrm{~mol} \%$ of TBPB at $210^{\circ} \mathrm{C}$ for $6 \mathrm{~h}$. ${ }^{\mathrm{b}}$ Measured by FT-IR spectrum. ${ }^{\mathrm{c}}$ Measured by DSC at heating rate of $10^{\circ} \mathrm{C} \mathrm{min}^{-1}$ under $\mathrm{N}_{2}$. ${ }^{\mathrm{d}}$ Measured by TGA at heating rate of $10^{\circ} \mathrm{C} \mathrm{min}^{-1}$ under $\mathrm{N}_{2}$.

summarized in Table VIII. Based on the conversions, the order on the efficiency of the curing reaction with calixarene derivatives at $210^{\circ} \mathrm{C}$ was as follows; 20a $>20 \mathrm{c}, 19 \mathrm{a}>19 \mathrm{c}, 19 \mathrm{~d}$. $T_{\mathrm{g}} \mathrm{s}$ of the obtained resins increased gradually as following order; 19a, 19d > $19 c, 20 a>20 c$. It seemed that the curing reactions did not proceed effectively in the late stage, that is, bulky acetyl or benzoyl groups of the cross-linked matrixes would hinder the reaction. $T_{\mathrm{g}} \mathrm{s}$ of the resulting resins were relatively lower than those of resins cured with calixarenes, due to the ester groups in the cross-linked resins. IDTs of the cured resins with the calixarenes containing ester groups were $340-365^{\circ} \mathrm{C}$. Thus, it was suggested that the cured resins have good thermal stability.

\section{Curing Reaction of Epoxy Resins with the Mixtures of Calixarenes and Calixarenes Containing Partial Ester Groups $^{44}$}

Curing reaction of Epikote 828 can be conducted with mixtures of calixarenes and calixarenes containing ester groups to obtain cured resins including hydroxyl groups and ester groups, which is expected to have good balances on the properties of $T_{\mathrm{g}}$, thermal property, water-absorbing property, mechanical properties, etc. The curing reaction with various ratios of mixtures of $C$-methylcalix[4]resorcinarene 1d and $C$-methylcalix[4]resorcinarene containing methyl ester groups 19d was carried out using $4 \mathrm{~mol} \%$ of TBPB at $210^{\circ} \mathrm{C}$ for $6 \mathrm{~h}$. As shown in Table IX, conversions of oxirane groups and $T_{\mathrm{g}} \mathrm{s}$ of the obtained resins increased with the ratio of $\mathbf{1 d}$. The decomposition temperatures of the obtained resins were about $365^{\circ} \mathrm{C}$ in all ratios of 1d and 19d.

Curing reaction of Epikote 828 with $C$ methyl[4]resorcinarenes containing partial methyl ester groups, 22d (50\% methyl ester) in the presence of $4 \mathrm{~mol} \%$ of TBPB were also conducted at various temperatures for $6 \mathrm{~h}$, and the results were summarized
Table X. Thermal properties of the cured resin of Epikote828 with 22d ${ }^{\mathrm{a}}$

\begin{tabular}{cccc}
\hline Curing temp. $\left({ }^{\circ} \mathrm{C}\right)$ & Conversion $(\%)^{\mathrm{b}}$ & $T_{\mathrm{g}}\left({ }^{\circ} \mathrm{C}\right)^{\mathrm{c}}$ & $T_{\mathrm{d}}\left({ }^{\circ} \mathrm{C}\right)^{\mathrm{d}}$ \\
\hline 150 & 77 & 175 & 361 \\
170 & 79 & 178 & 362 \\
190 & 84 & 185 & 366 \\
210 & 90 & 194 & 365 \\
\hline
\end{tabular}

${ }^{\mathrm{a}}$ This cured resin was given by thermal curing reaction of Epikote 828 with 22d using $4 \mathrm{~mol} \%$ of TBPB at $210^{\circ} \mathrm{C}$ for $6 \mathrm{~h}$. ${ }^{b}$ Measured by FT-IR spectrum. ${ }^{\mathrm{c}}$ Measured by DSC at heating rate of $10^{\circ} \mathrm{C} \mathrm{min}^{-1}$ under $\mathrm{N}_{2}$. ${ }^{\mathrm{d}}$ Measured by TGA at heating rate of $10^{\circ} \mathrm{C} \mathrm{min}^{-1}$ under $\mathrm{N}_{2}$.

in Table X. The conversions increased gradually with reaction temperatures, and the conversion reached $90 \%$ at $210^{\circ} \mathrm{C}$. The $T_{\mathrm{g}} \mathrm{s}$ of obtained resins also increased with the temperatures. This means that the conversions correspond to degrees of cross-linking in the curing system.

The characteristics of the curing system of epoxy resins with the calixarene derivatives as curing agents are summarized as follows. (1) The cured epoxy resins with calixarenes 1a, 1c, and 1d showed high $T_{\mathrm{g}}$ s. (2) The cured epoxy resins with the calixarenes containing active ester groups have lower $T_{\mathrm{g}} \mathrm{s}$ compared with those with 1a, 1c, and 1d. (3) In the case of curing of epoxy resins with mixtures of calixarenes and calixarenes containing ester groups, or calixarenes containing partially ester groups, the balance of high $T_{\mathrm{g}} \mathrm{s}$ can be controlled by the contents of ester groups of the calixarenes used.

\section{CONCLUSION}

The authors have developed successful synthetic methods of a variety of calixarene derivatives containing functional groups such as protective groups and various polymerizable groups. It was found that the novel calixarene derivatives had good thermal stability, which is an advantage as high performance materials. The photoinduced deprotection of the calixarenes containing protective groups such as $t$-Boc, TMS, and CHE groups readily proceeded to give the corresponding products. It was demonstrated that radical polymerization, cationic polymerization, and cationic ringopening polymerization of calixarene derivatives containing certain polymerizable groups could be achieved to give crosslinked materials with excellent thermal stability. The obtained materials are very useful as high performance materials for UV and EB curing systems. It was also presented that the calixarenes $1 \mathbf{a}, \mathbf{1 c}$, and 1d, and calixarenes containing active ester groups have high potentials as curing agents with good thermal stability for novel epoxy resin systems. The calixarene 
derivatives presented in this paper are useful materials for applications in the field of electronics, etc.

Acknowledgment. This work was partially supported by a Grant-in-aid for Scientific Research, in Japan (No13450385) from the Ministry of Education, Culture, Sports, Science and Technology, which is gratefully acknowledgment.

\section{REFERENCES}

1. C. D. Gutsche, Ed., "Calixarenes," Royal Society of Chemistry, Cambridge, 1989.

2. L. Mandolini and R. Ungaro, Ed., "Calixarenes in Action," Imperial College Press, London, 1999.

3. T. Arimura, S. Shinkai, and T. Matuda, J. Synth. Org. Chem. Jpn., 47, 523 (1989).

4. M. Takeshita and S. Shinkai, Bull. Chem. Soc. Jpn., 68, 1088 (1995).

5. P. Lhotak and S. Shinkai, J. Synth. Org. Chem. Jpn., 53, 523 (1995) .

6. S. Jacob, I. Majoros, and J. P. Kennedy, Macromolecules, 29, 8631 (1996) .

7. J. Ueda, M. Kamigaito, and M. Sawamoto, Macromolecules, 31, 6762 (1998) .

8. J. Fujita, Y. Onishi, Y. Ochiai, and S. Matsui, Appl. Phys. Lett., 68, 1297 (1996).

9. Y. Ochiai, S. Manako, H. Yamamoto, T. Teshima, J. Fujita, and E. Nomura, J. Photopolym. Sci. Techno1., 13, 413 (2000) .

10. T. Nishikubo, A. Kameyama, K. Tsutsui, and M. Iyo, J. Polym. Sci., Part A: Polym. Chem., 37, 1805 (1999) .

11. M. Iyo, K. Tsutsui, A. Kameyama, and T. Nishikubo, $J$. Polym. Sci., Part A: Polym. Chem., 37, 3071 (1999) .

12. C. G. Willson, H. Ito, M. J. Frechet, T. G. Tessier, and F. M. Houlihan, J. Electrochem. Soc., 133, 181 (1986).

13. T. Nakayama, K. Haga, O. Haba, and M. Ueda, Chem, Lett., 265 (1997).

14. M. Ueda, D. Takahashi, T. Nakamura, and O. Haba, Chem. Mater., 10, 2230 (1998) .

15. R. Nakayama, O. Haba, and M. Ueda, Polym. Prepr. Jpn., 47, 417 (1998).

16. K. Takeshi, R. Nakayama, and M. Ueda, Chem. Lett., 865 (1998).

17. T. Nakayama, M. Nomura, K. Haga, and M. Ueda, Bull. Chem. Soc. Jpn., 71, 2979 (1998).

18. T. Nishikubo, T. Ed., "Synthesis and Application of Photosensitive Polymers," CMC, Tokyo, 1979.

19. R. Holman and P. Oldring, Ed., "UV and EB Curings and Paints," International Training Associates Limited, London, 1998.
20. T. Ogasawara, Ed., "Synthesis and Application of Photosensitive Polymers, a Continuation," CMC, Tokyo, 1980, p 403.

21. T. Nishikubo, Ed., "Application and Market of UV and EB Curing Technology,” CMC, Tokyo, 1989, p 56.

22. R. R. Gulluci and R. C. Going, J. Org. Chem., 48, 342 (1983).

23. J. V. Crivello and D. A. Conlon, J. Polym. Sci., Polym. Chem. Ed., 21, 1785 (1983).

24. H. Ito, A. Kameyama, and T. Nishikubo, Macromolecules, 28, 883 (1995).

25. H. Ito, A. Kameyama, and T. Nishikubo, J. Polym. Sci., Part A: Polym. Chem., 33, 217 (1996).

26. H. Ito, A. Kameyama, and T. Nishikubo, J. Polym. Sci., Part A: Polym. Chem., 35, 3217 (1997).

27. J. V. Crivello and B. Yang, J. Polym. Sci., Part A: Polym. Chem., 33, 1381 (1995).

28. J. V. Crivello and B. Yang, J. Polym. Sci., Part A: Polym. Chem., 34, 2051 (1996).

29. T. Nishikubo, T. Iizawa, and Y. Sato, J. Polym. Sci., Part A: Polym. Chem. Ed., 21, 2291 (1983).

30. T. Nishikubo and K. Tanaka, J. Appl. Polym. Sci., 33, 2821 (1987).

31. T. Iizawa, A. Goto, and T. Nishikubo, Bull. Chem. Soc., Jpn., 62, 597 (1989).

32. T. Nishikubo, K. Kato, M. Tomoi, and S. Ishigaki, Polym. J., 21, 669 (1989).

33. T. Nishikubo, T. Iizawa, M. Shimojo, T. Kato, and A. Shiina, J. Org. Chem., 55, 2536 (1990).

34. S. Nakamura, Y. Saegusa, H. Yanagisawa, M. Touse, T. Shirai, and T. Nishikubo, Thermochem. Acta., 183, 269 (1991).

35. T. Nishikubo, A. Kameyama, K. Tsutsui, and S. Kishimoto, J. Polym. Sci., Part A: Polym. Chem., 39, 1481 (2001).

36. T. Yamaoka, M. Nishiki, and K. Koseki, Polym. Eng. Sci., 133, 181 (1986).

37. T. Nishikubo, A. Kameyama, and K. Tsutsui, J. Polym. Sci., Part A: Polym. Chem., 39, 1169 (2001).

38. T. Nishikubo, A. Kameyama, and K. Tsutsui, J. Polym. Sci., Part A: Polym. Chem., 40, 1293 (2002).

39. For example C. M. Starks and C. Liotta, Ed., "Phase Transfer Catalysis," Academic Press, Inc., New York, N.Y., 1978.

40. N. Isobe, T. Nishikubo, H. Tagoshi, and T. Endo, Macromol. Chem., 189, 287 (1988).

41. T. Nishikubo, S. Nakamura, A. Kameyama, and A. Komura, Prep. of 76th CSJ National Meeting, 1999, p 1351.

42. T. Adachi, A. Kameyama, S. Nakamura, and T. Nishikubo, Preprint of 76th CSJ National Meeting, 1999, p 1351.

43. T. Nishikubo and A. Kameyama, Prog. Polym. Sci., 18, 963 (1993).

44. N. Saito, H. Miyabe, A. Kameyama, and T. Nishikubo, Polym. Prepr., 50, 677 (2001). 


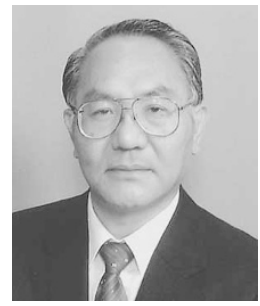

Tadatomi Nishikubo was born in Wakayama, Japan, in January 1th 1944. He received Bachelor degree in Chemistry from Kanagawa University, Japan in 1967. He joined NOK Co., Ltd, Japan in 1967. He received Doctorate degree in Polymer Chemistry from Tokyo Institute of Technology, Japan in 1976. His carrier at Kanagawa University has included being Lecturer (1978), Associate Professor (1980), and Full Professor (1986). He worked with Dr. R. W. Lenz as visiting faculty at the University of Massachusetts, USA in 1981-1982. Since 2000, he is the dean of the faculty of engineering of Kanagawa University. He has been the author of over 300 publications, including original research papers, reviews, and books. He has made 17 plenary and invited lectures at international scientific conferences. His research interest covers synthesis of new photofunctional polymers, new reaction of cyclic ethers, and synthesis of macromolecules with well-defined topological structures.
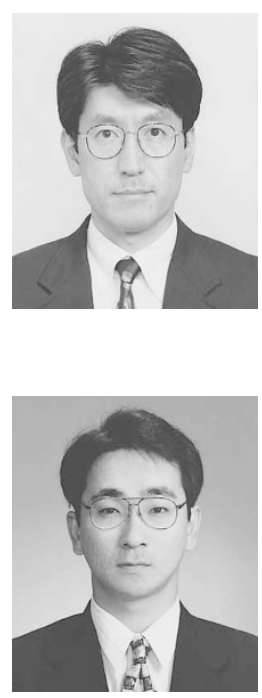

Atsushi Kameyama was born in Miyagi, Japan, in January 9th, 1959. He received his Doctorate Degree from Tokyo Institute of Technology, Japan in 1990. He did postdoctoral research at Cornell University, USA, with Professor Christopher K Ober (1995-1996). His carrier at Kanagawa University has included being Research Associate (1990) and Associate Professor (2000). He has published more than 124 papers in refereed scientific journals and 13 books and reviews. He has made an invited lecture at international scientific conferences. His research interest covers synthesis of polymers with well-defined structures, solid phase ring-opening polymerization of macrocyclic compounds, photocuring with hybrid type photoinitiators.

Hiroto Kudo was born in Oita, Japan, in May 21th 1970. He received Bachelor degree in Chemistry from Tokyo University of Agriculture and Technology, Japan in 1995. He received Master degree in Catalyst Chemistry from Tokyo Metropolitan University, Japan in 1997. He received Doctorate degree in Polymer Chemistry from Tokyo Institute of Technology, Japan in 2000. He did doctoral research at Venture Business Laboratory at Yamagata University, Japan in 2000-2001. Since 2001, he is research associate in Kanagawa University. He has published more than 20 papers in refereed scientific journal and 4 books and reviews. His research interest covers synthesis of new functional polymers derived from calixarenes, synthesis of amino-acid based on the polymers, new reaction of cyclic ethers, and synthesis of macromolecules with well-defined topological structures. 